\title{
Benchmark of Proton Exchange Membrane Fuel Cell Parameters Extraction with Metaheuristic Optimization Algorithms
}

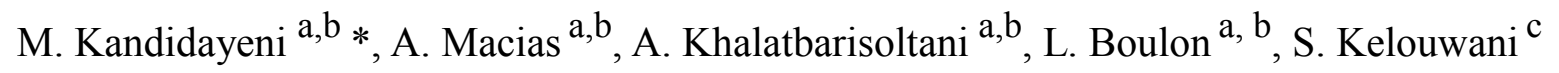

${ }^{a}$ Hydrogen Research Institute, Department of Electrical Engineering and Computer Science, Université du Québec à Trois-Rivières, Trois-Rivières, Québec, G9A 5H7, Canada

${ }^{\mathrm{b}}$ Canada Research Chair in Energy Sources for the Vehicles of the Future

${ }^{\mathrm{c}}$ Hydrogen Research Institute, Department of Mechanical Engineering, Université du Québec à Trois-Rivières, Trois-Rivières, Québec, G9A 5H7, Canada

* Corresponding author.

E-mail address: mohsen.kandi.dayeni@uqtr.ca (Mohsen Kandidayeni) 


\section{ABSTRACT}

Proton exchange membrane fuel cell (PEMFC) models are multivariate with different nonlinear elements which should be identified accurately to assure dependable modeling. Metaheuristic algorithms are perfect candidates for this purpose since they do an informed search for finding the parameters. This paper utilizes three algorithms, namely shuffled frog-leaping algorithm (SFLA), firefly optimization algorithm (FOA), and imperialist competitive algorithm (ICA) for the PEMFC model calibration. In this regard, firstly, the algorithms are employed to find the parameters of a benchmark PEMFC model by minimizing the sum of squared errors (SSE) between the measured and estimated voltage for two available case studies in the literature. After conducting 100 independent runs, the algorithms are compared in terms of the best and the worst SSEs, the variance, and standard deviation. This comparison indicates that SFLA marginally outperforms ICA and FOA regarding the best SSE in both cases while it performs $20 \%$ and twofold better than other algorithms concerning the worst SSE. Furthermore, the obtained variance and standard deviation by SFLA are much less than the other algorithms showing the precision and repeatability of this method. Finally, SFLA is used to calibrate the model for a new case study (Horizon 500-W PEMFC) with variable temperature.

Keywords: metaheuristic algorithms, shuffled frog-leaping algorithm, PEMFC, semi-empirical modeling

\section{Introduction}

Exhaustion of fossil fuels, owing to the growth of energy consumption, and the gained public insights into environmental protection have turned the attentions of both individual and governmental sectors to alternative sources of energy [1]. As a result, many researchers have been engrossed by greener energy sources such as wind, solar, waves, and so forth [2]. The major problems with the stated sources are their unforeseeable nature and reliance on climate conditions. These pitfalls, on the other hand, have marked the paramount need of energy storage. Hydrogen, which is the trending topic nowadays, can operate as an energy storage medium to efficiently store renewable energy until an energy conversion device turns it into 
electricity [3]. Fuel cell (FC) is one of the most significant conversion devices, which usually produces electricity through a chemical reaction between hydrogen and oxygen. Among different kinds of FCs, proton exchange membrane FC (PEMFC) has been used in a number of areas such as automotive, on-site generation, and portable electronic devices because of its low operating temperature, high power density, and solid electrolyte $[4,5]$.

One of the key issues in the technical maturity of PEMFCs is their mathematical modeling. Modeling can disclose more details about the operation of this device resulting in a better appreciation of the performance enhancement $[6,7]$. One of the most important challenges through the process of modeling a PEMFC is the precise estimation of its characteristics [8]. This difficulty is mainly owing to the fact that PEMFC is a multiphysics system and its parameters are strictly related to the operating conditions [9-11]. Although there are many approaches for the PEMFC modeling, such as mechanistic and black-box [12], mathematical modeling based on semi-empirical equations have been given a lot of attentions due to their capabilities to mimic the behavior of this device in variant operating conditions [13]. Unlike the mechanistic models, which offer deep apprehension of the underlying phenomena, and black box models, which provides shallow insight into heat and mass phenomena, semi-empirical models attempt to illuminate the electrochemical behavior of a FC by imitating the polarization curve [14]. So far, several semi-empirical models have been proposed to predict the polarization curve $[15,16]$. Among them, the model introduced by Amphlett et al. [17], which is a semi-empirical model supported by a mechanistic background, has been used in many studies and its parameters estimation has become a benchmark problem in this field [18]. A number of similar suggested models in the literature can result in a satisfactory prediction for a particular FC system. However, few of them have had this wide application. The topical issue related to this model and modeling approach is the inaccessibility of the exact parameters. Hence, the proper calibration of model parameters has a vital role in achieving accurate output. Several methods, such as artificial neural networks, adaptive filters, and experimental electrochemical approaches, have been used for modeling and parameter extraction of PEMFCs as described completely in [19]. Among them, metaheuristic optimization algorithms 
have been the focus of many studies for offline identification due to their robustness, flexibility, and parallel computing for extracting the linear and nonlinear parameters of a PEMFC model [20-22]. These methods are utilized as an alternative to conventional derivative-based techniques. They are quite appropriate for global searches due to their potential at exploration and discovering promising domains in the defined search space at a particular time. The majority of the metaheuristic optimization techniques are natureinspired. Although they offer near optimal rather than optimal solutions, they do not need the cost function derivatives and/or constraints and employ deterministic rules to solve nonlinear and nonconvex problems [23]. Another worth noting applicability of parameter extraction by metaheuristic algorithms is that the obtained set of parameters by these algorithms can be used as initial values for online adaptive filter based parameter identification to enhance the performance $[19,24]$. This stems from the fact that the performance of adaptive filters is very sensitive to the initialization stage, and they do not have the same exploration capability as metaheuristic algorithms to find the suitable parameters [25]. A comprehensive review of the utilized optimization algorithms in the parameter estimation of semi-empirical PEMFC models can be found in [26]. Table 1 lists some of these algorithms in recent years along with the utilized PEMFC case studies.

Table 1: The studied metaheuristic algorithms for PEMFC parameters extraction

\begin{tabular}{cccc}
\hline Optimization Algorithm & Case study & Year & Reference \\
\hline Eagle strategy & A PEMFC stack [27] & 2019 & {$[28]$} \\
A PEMFC stack [27] & & \\
Cuckoo search algorithm with explosion operator & SR-12 500 W & 2019 & {$[29]$} \\
(CS-EO) & Ballard Mark V (1 cell) & & \\
BCS 500 W & & \\
Slap swarm optimizer (SSO) & NedStack PS6 & 2018 & {$[30]$} \\
Grasshopper optimization (GHO) & BCS 500 W & 2018 & {$[31]$} \\
& & & \\
Grey wolf optimizer (GWO) & 250-W PEMFC & & \\
& Ballard V 5 kW & 2017 & {$[32]$} \\
SR-12 500 W & & \\
Aging and challenging P systems based optimization & BCS 500 W & & \\
algorithm (AC-POA) & Temasek 1 kW & 2016 & {$[33]$} \\
Hybrid teaching learning based optimization - & 250-W PEMFC & 2016 \\
differential evolution (TLBO-DE) & 250-W PEMFC & 2016 & {$[34]$}
\end{tabular}




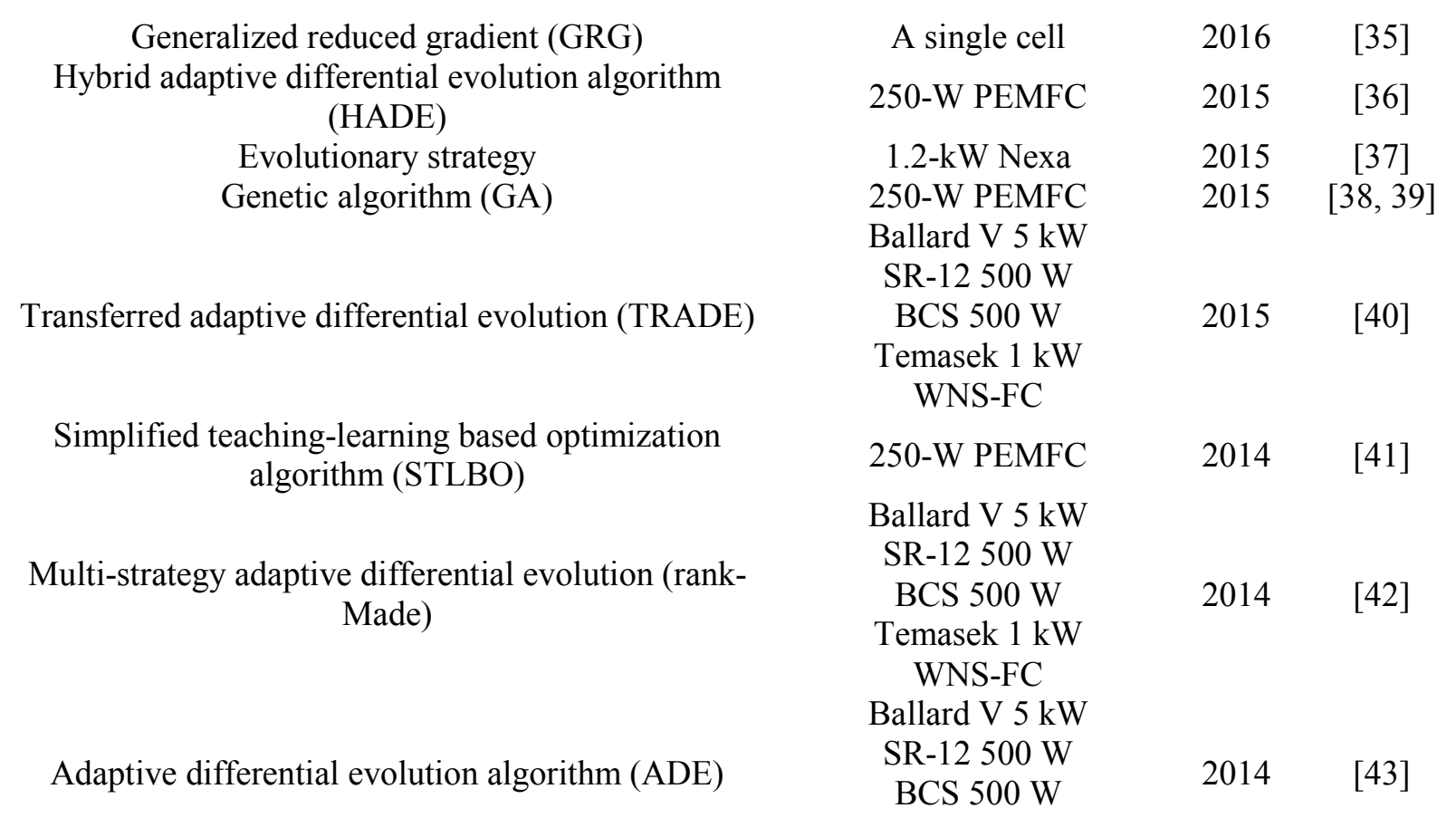

The literature study evidently demonstrates the application and significance of metaheuristic algorithms in the PEMFC parameter estimation problem. So far, no optimization algorithm has been proved to be the most proper and accordingly there is always this necessity to evaluate the performance of any newly developed optimization methods for exploring the optimal solution of a specific problem under attention.

This paper aims at investigating the performance of three metaheuristic algorithms, namely shuffled frogleaping algorithm (SFLA), firefly optimization algorithm (FOA), and imperialist competitive algorithm (ICA), in the parameters estimation benchmark of the PEMFC model proposed by Amphlett et al. These algorithms have been used in several engineering problems. However, to the best of the authors' knowledge, this is the first attempt to identify the parameters of a FC system by means of the mentioned algorithms. Herein, the stated algorithms are exploited to estimate the Amphlett's model parameters for the experimental data of NedStack PS6 (6 kW), and BCS 500-W PEM generator, which are available in the literature, and Horizon 500-W open cathode PEMFC, which is accessible on a developed test bench for this work. The performance of the algorithms has been compared with one another for a defined fitness function 
over 100 independent runs to investigate the accuracy and probability of repeating the satisfying solution. It should be noted that the introduced algorithms performance has been also compared with very recent used optimizers in PEMFC modeling, such as SSO, GHO, and GWO, for the common case studies.

The remainder of this paper is structured as follows. A general description of the benchmark PEFMC modeling problem is provided in section 2 . The explanation of algorithms is presented in section 3 . Section 4 deals with the investigation of the obtained results regarding the comparison of the algorithms and the PEMFC case studies. Finally, the conclusion is given in section 5.

\section{Mathematical PEMFC stack modeling}

The steady-state behavior of the PEMFC has been modeled by means of an electrochemical model proposed by Amphlett et al. in $[17,44]$. In this model, the output voltage of the PEMFC $\left(V_{F C}\right)$ is considered as the sum of cell reversible voltage $\left(E_{\text {Nernst }}\right)$ and three voltage losses, namely activation $\left(V_{A c t}\right)$, ohmic $\left(V_{\text {Ohmic }}\right)$, and concentration $\left(V_{C o n}\right)$. This model is for a number of cells $\left(N_{c e l l}\right)$ connected in series and considers the same behavior for all the cells. The general formulation of the utilized electrochemical model is as follows:

$V_{F C}=N_{c e l l}\left(E_{\text {Nernst }}-V_{\text {Act }}-V_{\text {Ohmic }}-V_{\text {Con }}\right)$

Where the Nernst equation, which calculates the thermodynamic potential, is formulated based on [28, 44]:

$E_{\text {Nernst }}=1.229-0.85 \times 10^{-3}\left(T_{\text {stack }}-298.15\right)+4.3085 \times 10^{-5} T_{\text {stack }}\left[\ln \left(P_{H 2}\right)+0.5 \ln \left(P_{O 2}\right)\right](2)$

Where $T_{\text {stack }}$ is the stack temperature $(\mathrm{K}), P_{H 2}$ is the hydrogen partial pressure in anode side (atm), and $P_{O 2}$ is the oxygen partial pressure in cathode side (atm).

The reactant partial pressures in the inlet flow channels will vary with the humidification level of the inlet streams, and the consumption rates of oxygen and hydrogen [17, 44]. Under such basis, if the utilized reactants are air and Hydrogen, which is the case in this work and the majority of the utilized PEMFC systems, $P_{O 2}$ can be calculated as $[27-29,33,34,38]$ : 
$P_{O 2}=P_{C}-\left(R H_{C} P_{H_{2} O}^{s a t}\right)-\frac{0.79}{0.21} P_{O 2} \exp \left(\frac{0.291\left(I_{F C} / A\right)}{T_{\text {stack }} \text { o.832 }}\right) \quad$ (air and $\left.\mathrm{H}_{2}\right)$

If the reactants are Oxygen and Hydrogen, then $P_{O 2}$ is obtained as $[27-29,33,34,38]$ :

$P_{O 2}=R H_{C} P_{H_{2} O}^{s a t}\left[\left(\exp \left(\frac{4.192\left(I_{F C} / A\right)}{T_{\text {stack }}{ }^{1.334}}\right) \times \frac{R H_{C} P_{H_{2} O}^{\text {sat }}}{P_{C}}\right)^{-1}-1\right]\left(\mathrm{O}_{2}\right.$ and $\left.\mathrm{H}_{2}\right)$

In both cases, the $P_{H 2}$ is given by $[27-29,33,34,38]$ :

$P_{H_{2}}=0.5 R H_{a} P_{H_{2} O}^{\text {sat }}\left[\left(\exp \left(\frac{1.635\left(I_{F C} / A\right)}{T_{\text {stack }}{ }^{1.334}}\right) \times \frac{R H_{C} P_{H_{2} O}^{s a t}}{P_{a}}\right)^{-1}-1\right]$

Where $R H_{C}$ and $R H_{a}$ are relative humidity of vapor in electrodes, $P_{C}$ and $P_{a}$ are the cathode and anode inlet partial pressures (atm), $I_{F C}$ is the PEMFC operating current (A), $A$ is the active area of the membrane $\left(\mathrm{cm}^{2}\right)$, and $P_{H_{2} \mathrm{O}}^{s a t}$ is the saturation water pressure (atm). The saturation vapor pressure at the FC operating temperature can be defined as $[27,45]$ :

$$
\begin{aligned}
& \log _{10}\left(P_{H_{2} O}^{\text {sat }}\right)=2.95 \times 10^{-2}\left(T_{\text {stack }}-273.15\right)-9.18 \times 10^{-5}\left(T_{\text {stack }}-273.15\right)^{2}+1.44 \times \\
& 10^{-7}\left(T_{\text {stack }}-273.15\right)^{3}-2.18
\end{aligned}
$$

The activation loss is the overpotential required to activate the electrodes. This loss is dominant in low current density region and is calculated by:

$$
\left\{\begin{array}{l}
V_{\text {Act }}=-\left[\xi_{1}+\xi_{2} T_{\text {stack }}+\xi_{3} T_{\text {stack }} \ln \left(\mathrm{Co}_{2}\right)+\xi_{4} T_{\text {stack }} \ln \left(I_{F C}\right)\right] \\
C o_{2}=\frac{P o_{2}}{5.08 \times 10^{6} \exp \left(-498 / T_{\text {stack }}\right)}
\end{array}\right.
$$

Where $\mathrm{Co}_{2}$ is the oxygen concentration $\left(\mathrm{mol} \mathrm{cm}^{-3}\right)$, and $\xi_{k}(\mathrm{k}=1 \ldots 4)$ are the semi-empirical coefficients based on theoretical equations with kinetic, thermodynamic, and electrochemical foundations [17]. These parameters have been already defined in the literature $[17,44,46]$ by solving the Butler-Volmer equation, which is a thermodynamics relation based on transfer coefficient, exchange current density, universal gas constant, Faraday constant, and number of electrons transferred due to reaction, etc., for both of anode and cathode reaction sides. The ohmic voltage drop, which is the consequence of resistance to the electrons 
transfer through the collecting plates and carbon electrodes and the resistance to the protons transfer through the solid membrane, is calculated by a general expression based on the equivalent resistance of the membrane [44]:

$$
\left\{\begin{array}{l}
V_{\text {Ohmic }}=I_{F C}\left(R_{m}+R_{C}\right) \\
R_{m}=\rho_{m} l / A \\
\rho_{m}=\frac{181.6\left[1+0.03(J)+0.062\left(T_{\text {stack }} / 303\right)^{2}(J)^{2.5}\right]}{[\lambda-0.643-3(J)] \exp \left(4.18\left(\frac{T_{\text {stack }}-303}{T_{\text {stack }}}\right)\right)}
\end{array}\right.
$$

Where $R_{m}$ is the membrane resistance $(\Omega), R_{C}$ is the equivalent contact resistance to electron conduction $(\Omega), \rho_{m}$ is the resistivity of the membrane ( $\left.\Omega . \mathrm{cm}\right), l$ is the membrane thickness, $J$ is the actual current density $\left(\mathrm{A} \mathrm{cm}^{-2}\right.$ ), and $\lambda$ is an adjustable parameter related to the water content of the membrane. $R_{C}$ is usually considered as constant. However, $\lambda$ is an adaptable parameter related to the membrane and its preparation process. It is a function of relative humidity and stoichiometry relation of the anode gas. As reported in [28, $36,38,40,41,47]$, its value ranges from 10 to 23 where lower values signify high relative humidity ratio and higher values indicates oversaturated conditions.

The concentration voltage drop is indeed due to the mass transport which influences the concentrations of hydrogen and oxygen and, as a result, reduces the partial pressure of these gases. Oxygen and hydrogen pressures drop relies on the electrical current and the physical characteristics of the system. To determine an equation for this drop, a maximum current density is defined based on which the current density cannot surpass this limit since the fuel cannot be provided at a higher rate. $V_{C o n}$ is determined by:

$V_{\text {Con }}=-\beta \ln \left(J_{\max }-J / J_{\max }\right)$

Where $\beta$ is a parametric coefficient (V) that depends on the cell and its operation state [48], and $J_{\max }$ is the maximum current density. The parameters which need to be extracted in the discussed steady-state model are listed in Table 2. This table also clarifies the maximum and minimum range of each parameter. 
Table2: Range of targeted parameters for estimation

\begin{tabular}{ccccc}
\hline Model & Parameters & Minimum & Maximum & Reference \\
\hline & $\xi_{1}$ & -1.1997 & -0.8532 & \\
& $\xi_{2} \times 10^{-3}$ & 1 & 5 & \\
& $\xi_{3} \times 10^{-5}$ & 3.6 & 9.8 & \\
Semi-empirical & $\xi_{4} \times 10^{-5}$ & -26 & -9.54 & {$[28-30,32,34,36,38,40,41]$} \\
& $R_{C}(\Omega) \times 10^{-4}$ & 1 & 8 & \\
& $\lambda$ & 10 & 23 & \\
& $\beta(\mathrm{V})$ & 0.0136 & 0.5 & \\
\hline
\end{tabular}

\section{Metaheuristic optimization algorithms}

Constrained optimization is a vital part of most of the engineering and industrial problems [49]. In this type of problem, the mathematical optimization is defined by different kinds of constraints which modify the form of the search space. The metaheuristic optimization techniques are usually used to find global or nearglobal answers in such problems. In this work, SFLA, ICA, and FOA algorithms are used in PEMFC parameter extraction. This is a new application for these algorithms. They have shown satisfactory performance in other engineering problems. Therefore, it is worthwhile to use them in PEMFC modeling, which is a highly nonlinear problem. The performance of these algorithms is assessed based on a defined fitness function for 100 independent runs to show their robustness.

\subsection{Fitness function definition}

The optimization problem is normally defined by introducing a fitness function as the objective of minimization, the decision variables as the targeted parameters of estimation, and the search space formed by the upper and lower limits of each decision variable. The optimization algorithms use the fitness function to direct the population towards better solutions. The main goal of the fitness function definition, based on which all the algorithms are compared, is to extract the steady-state model parameters by minimizing the sum of squared errors (SSE) between the output voltage of each PEMFC stack and the estimated voltage by the model. The main reason for defining such fitness function is that it is commonly used in the literature 
[26] and makes the results of this work comparable to the existing optimizers in other manuscripts. This fitness function can be formulated by:

$$
\left\{\begin{array}{l}
\text { min } \\
\left(\begin{array}{c}
\text { steady }- \text { state } \\
\text { params. }
\end{array}\right) \sum_{i=1}^{N}\left(V_{F C, \text { meas }}(i)-V_{F C, \text { est }}(i)\right)^{2} \\
\xi_{k, \text { min }} \leq \xi_{k} \leq \xi_{k, \text { max }}(\mathrm{k}=1 \ldots 4) \\
R_{C, \text { min }} \leq R_{C} \leq R_{C, \text { max }} \\
\lambda_{\text {min }} \leq \lambda \leq \lambda_{\max } \\
\beta_{\text {min }} \leq \beta \leq \beta_{\text {max }}
\end{array}\right.
$$

where $V_{F C \text {,meas }}$ is the measured output voltage, $V_{F C \text {,est }}$ is the estimated output voltage by the model, and $N$ is the number of sample data. The suitability of the estimated parameters value is scrutinized by testing the described PEMFC models in MATLAB software. It should be noted that selecting appropriate initial values for the parameters has a significant role in the quality of the estimation process. In this work, the fitness function is exposed to practical inequality constraints defined by the upper and lower bounds.

\subsection{Shuffled frog-leaping algorithm}

SFLA is considered as a memetic metaheuristic method put forward to find a global optimal answer by conducting an informed search [50]. It integrates the virtue of particle swarm optimization local search into the idea of combining the information from parallel local searches to a global solution. The population in SFLA is composed of a number of frogs/solutions, which are divided into some subsets known as memeplexes. Each memeplexe is the representative of a group of frogs performing a local search. Each individual frog inside of a memeplexe has an idea affected by the ideas of other individuals. This idea is improved through a memetic evolution. After a specific number of steps, ideas are shared among the memeplexes by means of a shuffling process. The process of shuffling as well as the local search are sustained until the expected convergence criteria are satisfied. Figure 1 shows the flowchart of the SFLA. According to this flowchart, an initial population is first generated randomly $(P)$ within the search space. In multidimensional problems, each frog $i$ is defined by $S$ variables as $X_{i}=\left(x_{i 1}, x_{i 2}, \ldots, x_{i S}\right)$. The frogs are then put in a descending order with respect to their achieved fitness. After that the whole population is 
partitioned into $m$ memeplexes, where each one includes $n$ frogs $(P=m \times n)$. Each frog is placed into its corresponded memeplex, i.e. the first frog in the first memeplex, the second frog in the second memeplex, and the $m$ th frog in the $m$ th memeplex. The frog $m+1$ is sent back to the first memeplex again, and this continues until each frog finds a place in each memeplex. Inside each memeplex, the individual frogs with the best $X_{b}$, worst $X_{w}$, and global best $X_{g}$ finesses are determined and only the one with the worst fitness is improved as follows:

$D_{i}=\operatorname{randn}\left(X_{b}-X_{w}\right)$

$X_{w, \text { new }}=X_{w, \text { present }}+D_{i} \quad\left(-D_{\max } \leq D_{i} \leq D_{\max }\right)$

where $D_{i}$ is the frog position change, $r n d$ is a random number between 0 and $1, X_{w, \text { new }}$ is the new position of the frog with the worst fitness inside the feasible space, $X_{w, p r e s e n t}$ is the current position of the frog with the worst fitness, and $D_{\max }$ is the maximum possible variation in the position of a frog. It should be noted that if the formulated evolution results in a better solution, it replaces the worst solution. Otherwise, the equations (11) and (12) are repeated for the case that $X_{b}$ is replaced by $X_{g}$. In case of observing no improvement in the solution after trying the two mentioned scenarios, a new random solution is generated instead of the frog with the worst solution. The calculation is then continued for a particular number of iterations. The principal parameters of the SFLA are the population or the number of frogs, number of memeplexes, and maximum iteration for each memeplexe. 


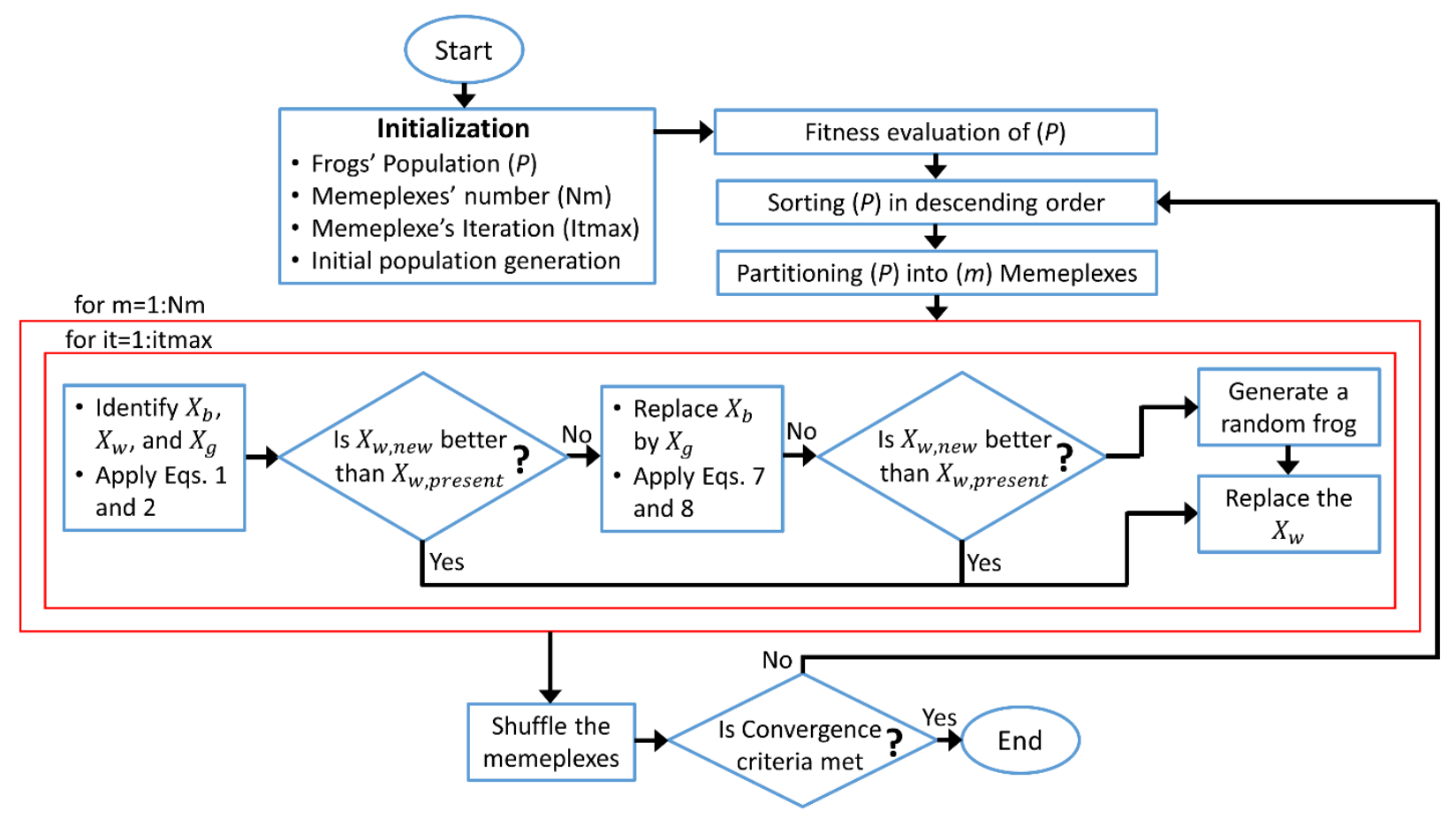

Figure 1: SFLA flowchart

\subsection{Imperialist competitive algorithm}

ICA is an imperialistic inspired method which has been successfully implemented in different engineering problems $[51,52]$. The flowchart of this algorithm is shown in Figure 2. This algorithm commences by generating some random solutions, known as countries containing the optimization problem variables $\left(p_{1}, p_{2}, \ldots, p_{N_{v a r}}\right)$, in the search space. $N_{\text {var }}$ is the dimension of the problem. The initial countries are then divided into two classes of imperialist and colony according to their power which is determined by the defined cost function of the optimization problem.

Country $=\left[p_{1}, p_{2}, \ldots, p_{N_{v a r}}\right]$

$\operatorname{Cost}=f\left(p_{1}, p_{2}, \ldots, p_{N_{\text {var }}}\right)$

The primary empires are established by distributing the colonies among the imperialists. The colonies are divided among the imperialists proportionally by: 
$C_{n}=c_{n}-\max \left\{c_{i}\right\}$

$p_{n}=\left|C_{n} / \sum_{i=1}^{N_{i m p}} C_{i}\right|$

$N C_{n}=\operatorname{round}\left\{p_{n} N_{c o l}\right\}$

where $c_{n}$ and $C_{n}$ are the $n$th imperialist cost and normalized cost respectively, $p_{n}$ is the normalized power of each imperialist, $N_{i m p}$ is the number of imperialists, $N C_{n}$ is the $n$th empire initial number of colonies chosen randomly, and $N_{c o l}$ is the number of colonies. The empires then go thorough assimilation and revolution processes in which colonies move towards the states of the imperialists with random characteristics. If a colony reaches a better position than its corresponding imperialist (considering the cost function), they exchange positions. The movement of colonies and total power of an empire can be formulated by:

$\{x\}_{\text {new }}=\{x\}_{\text {old }}+U(0, \sigma \times d) \times\left\{V_{1}\right\}$

$\theta=U(-\gamma,+\gamma)$

$T C_{n}=f_{\text {cost }}^{(i m p, n)}+\psi\left(\sum_{i=1}^{N C_{n}} f_{\text {cost }}^{(\text {coli })} / N C_{n}\right)$

where $\sigma$ is a parameter greater than one, $d$ is the distance between colony and imperialist, $\left\{V_{1}\right\}$ is a vector with unity length, $\theta$ is a random number with uniform distribution added to the direction of movement to enhance the searching around the imperialist, $\gamma$ is a parameter that modifies the deviation from the original direction, $T C_{n}$ is the total cost of the $n$th empire, and $\psi$ is a positive number less than one. The values of 2 , 0.1 , and 0.1 have been found to be good for $\sigma, \gamma$, and $\psi$ respectively. The imperialistic competition slowly decreases the power of weaker empires and increases the power of more powerful ones by choosing the weakest colony of the weakest empire and giving it to the empire with the most possession probability $\left(P_{n}\right)$. When an empire loses all its colonies, it will be eliminated. The normalized total cost and the possession probability of each empire are given by: 
$N T C_{n}=T C_{n}-\max \left(T C_{i}\right)$

$P_{n}=\left|N T C_{n} / \sum_{i=1}^{N_{i m p}} N T C_{i}\right|$

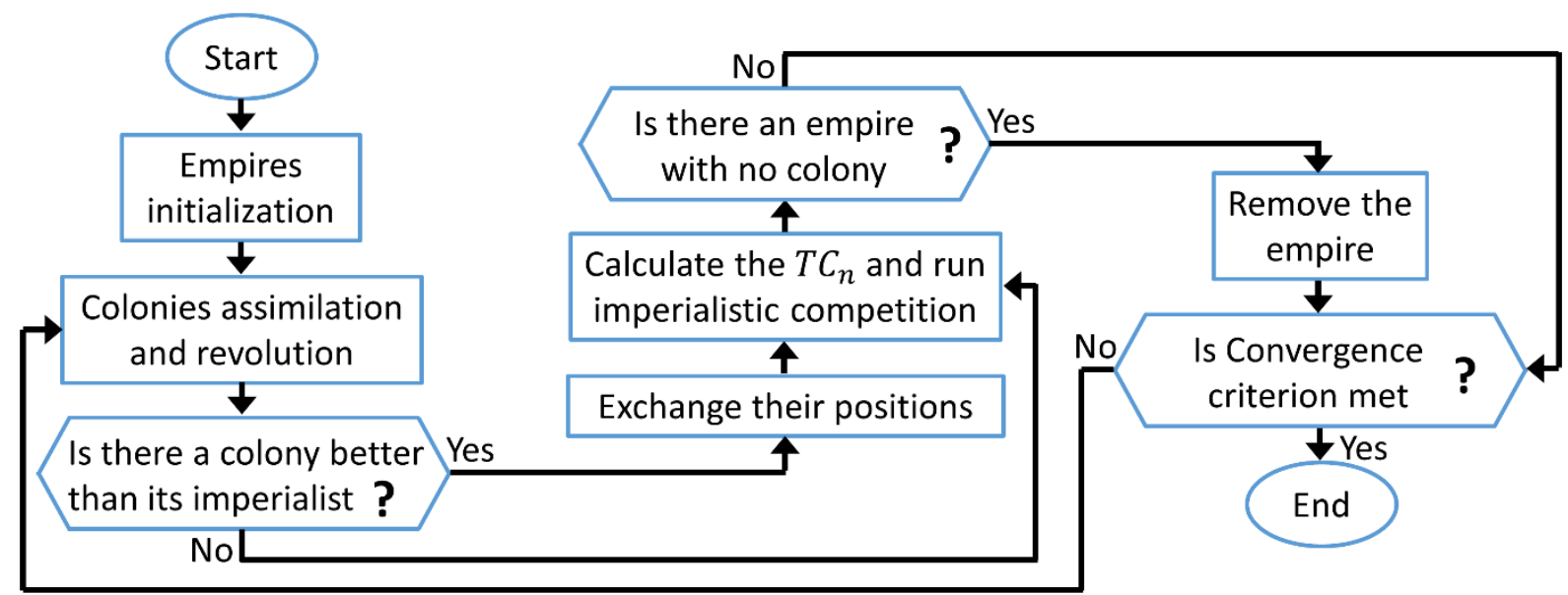

Figure 2: ICA flowchart

\subsection{Firefly Optimization Algorithm}

FOA is a metaheuristic algorithm premised on the social behavior of fireflies for attracting mates [53]. FOA is based on three fundamental presumptions. First, all the fireflies are perceived as unisex and try to approach the brighter ones until the whole population is compared. Second, the attraction of the fireflies is associated with the potency of their flash signals. This means that in case of having the choice for moving towards two fireflies, the brighter one is preferred. It should be noted that the brightness declines as the distance increases. Third, brightness intensity of a firefly is calculated by the value of the optimization problem fitness function. The FOA can be mathematically presented by the following equations:

$$
\begin{aligned}
& \omega(r)=\omega_{0} \exp \left(-\kappa r^{m}\right), m \geq 1 \\
& r_{i j}=\sqrt{\sum_{k=1}^{d}\left(x_{i, k}-x_{j, k}\right)^{2}} \\
& x_{i}=x_{i}+\omega_{0} \exp \left(-\kappa r_{i j}^{2}\right)\left(x_{j}-x_{i}\right)+\alpha(\operatorname{randn}-1 / 2)
\end{aligned}
$$


Where $\omega(r)$ is the attractiveness, $r$ is the distance between two fireflies, $\omega_{0}$ is the initial attractiveness when $r$ is zero, $\kappa$ is a fixed light absorption factor, $d$ is the dimension of the problem, $x_{i}$ and $x_{j}$ are the positions of two $i$ and $j$ fireflies, $\alpha$ is a value between zero and one, and randn is a random number generator uniformly and distributed between $[0,1]$. Figure 3 presents the flowchart of the FOA.

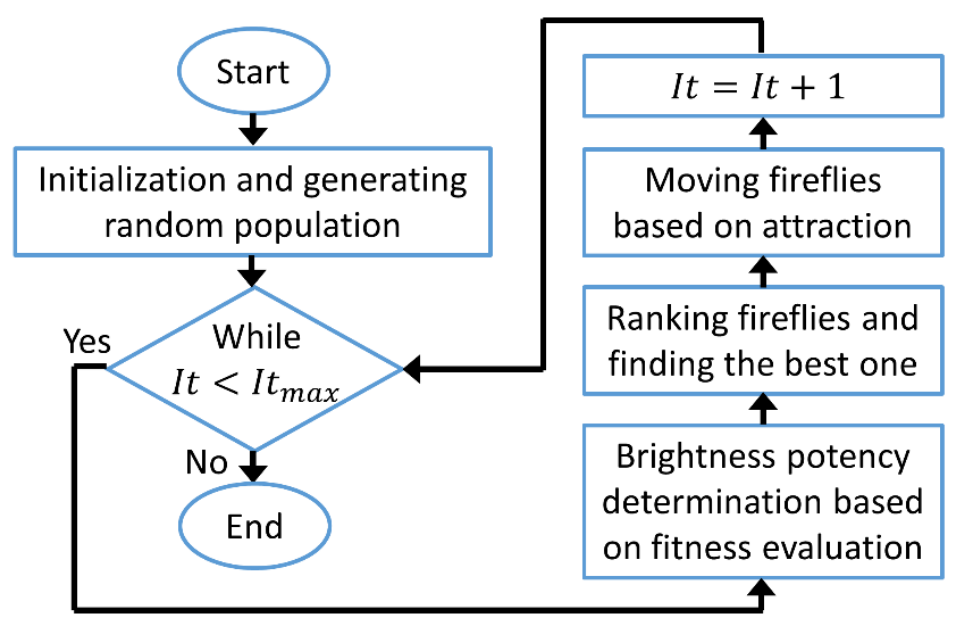

Figure 3: FOA flowchart

\section{Results and discussion}

This section presents the achieved results from different parts of the manuscript. First, the results related to the available PEMFC case studies in the literature are investigated, and the algorithms are compared. Subsequently, the data related to the proposed case study of this work, which is a 500-W Horizon PEMFC, is presented along with the description of the utilized test bench for recording the measured data. Finally, the estimation quality of the open cathode PEMFC is studied. It should be noted that the controlling parameters used for each algorithm are listed in Table 3. These parameters have been obtained based on the introduced reference papers and trials and errors over several runs. These algorithms might show better or worse performance by changing the controlling parameters and that is why they are clarified in Table 3. Another worth noting aspect is that since the metaheuristic techniques intrinsically have high level of randomness, 100 independent runs are done for each algorithm and the best result is then chosen out of 
these tries. The robustness of the algorithms is investigated by means of some statistical factors, such as variance and standard deviation of the defined fitness function. Moreover, the point-by-point measured data, which are the input of the algorithms, are reported for all the case studies.

Table 3: Controlling parameters of the utilized algorithms

\begin{tabular}{|c|c|c|c|c|c|}
\hline \multicolumn{2}{|l|}{ SFLA } & \multicolumn{2}{|l|}{ ICA } & \multicolumn{2}{|l|}{ FOA } \\
\hline Parameter & Value & Parameter & Value & Parameter & Value \\
\hline Maximum iteration & 100 & Maximum iteration & 100 & Maximum iteration & 100 \\
\hline Frog population & 50 & Number of countries & 50 & Number of fireflies & 50 \\
\hline $\begin{array}{l}\text { Number of } \\
\text { Memeplexes }\end{array}$ & 5 & $\begin{array}{l}\text { Number of } \\
\text { imperialists }\end{array}$ & 10 & $\begin{array}{l}\text { Light Absorption } \\
\text { Coefficient }\end{array}$ & 1 \\
\hline $\begin{array}{l}\text { Memes in } \\
\text { Memeplexes }\end{array}$ & 10 & $\begin{array}{l}\text { Assimilation } \\
\text { coefficient }\end{array}$ & 2 & $\begin{array}{l}\text { Attraction coefficient base } \\
\text { value }\end{array}$ & 2 \\
\hline Memetic evolutions & 10 & $\begin{array}{l}\text { Revolution } \\
\text { probability }\end{array}$ & 0.1 & Mutation coefficient & 0.2 \\
\hline
\end{tabular}

\subsection{Case study 1 (NedSstack PS6)}

This case study belongs to a NedSstack PS6 PEMFC stack with the rated power of $6 \mathrm{~kW}$. The operating data of this PEMFC system can be found in [30], and its characteristics are as follows: $N_{\text {cell }}=65, P_{H 2}=1$ $\mathrm{atm}, P_{O 2}=1 \mathrm{~atm}, T_{\text {stack }}=343 \mathrm{~K}, A=240 \mathrm{~cm}^{2}, l=178 \mu \mathrm{m}$, and $J_{\max }=0.918 \mathrm{~A} \mathrm{~cm}^{-2}$. The maximum operating current of this PEMFC is $225 \mathrm{~A}$. Table 4 indicates the obtained values for each targeted parameter after implementing the algorithms for parameter extraction process. This table also shows the best fitness value attained by each algorithm, which corresponds to the reported estimated parameters. The obtained best solutions by the introduced algorithms in this work shows that they have considerable accuracy in terms of extracting the parameters of this PEMFC system. The estimated polarization curve of the NedSstack PS6 PEMFC stack by SFLA algorithm is shown in Figure 4a. SFLA has reached the best fitness value, which is the minimum SSE between measured and predicted voltage. It is worth mentioning that the point-by-point current-voltage values obtained by all of the three algorithms are also reported in Table A.1 in the appendix section. The fitness function convergence trend for different algorithms is presented in Figure $4 \mathrm{~b}$. With regard to this figure, the fitness value minimization trend has become almost stable after 20 iterations by all the algorithms. 
Table 4: The estimated parameters along with the best fitness value

\begin{tabular}{ccccccc}
\hline Parameter & SFLA & ICA & FOA & SSO [30] & GHO [31] & GA [31] \\
\hline$\xi_{1}$ & -1.023071 & -1.034322 & -1.035664 & -0.9719 & -1.1997 & -1.1997 \\
$\xi_{2} \times 10^{-3}$ & 3.4760 & 3.3202 & 2.9502 & 3.3487 & 3.5505 & 3.4172 \\
$\xi_{3} \times 10^{-5}$ & 7.7883354 & 6.4420795 & 3.7669451 & 7.9111 & 4.6144 & 3.6000 \\
$\xi_{4} \times 10^{-5}$ & -9.540000 & -9.540000 & -9.540000 & -9.5435 & -9.5400 & -9.5400 \\
$R_{C}(\Omega) \times 10^{-4}$ & 1.62 & 1.65 & 1.622 & 1.000 & 1.005 & 1.376 \\
$\lambda$ & 15.03229 & 15.09701 & 15.029691 & 13.0000 & 13.0092 & 13.0000 \\
$\beta(\mathrm{V})$ & 0.013600 & 0.013600 & 0.0136000 & 0.0534 & 0.0579 & 0.0359 \\
Best fitness (SSE) & 2.167055 & 2.168339 & 2.167091 & 2.18067 & 2.18586 & 2.4089 \\
\hline
\end{tabular}
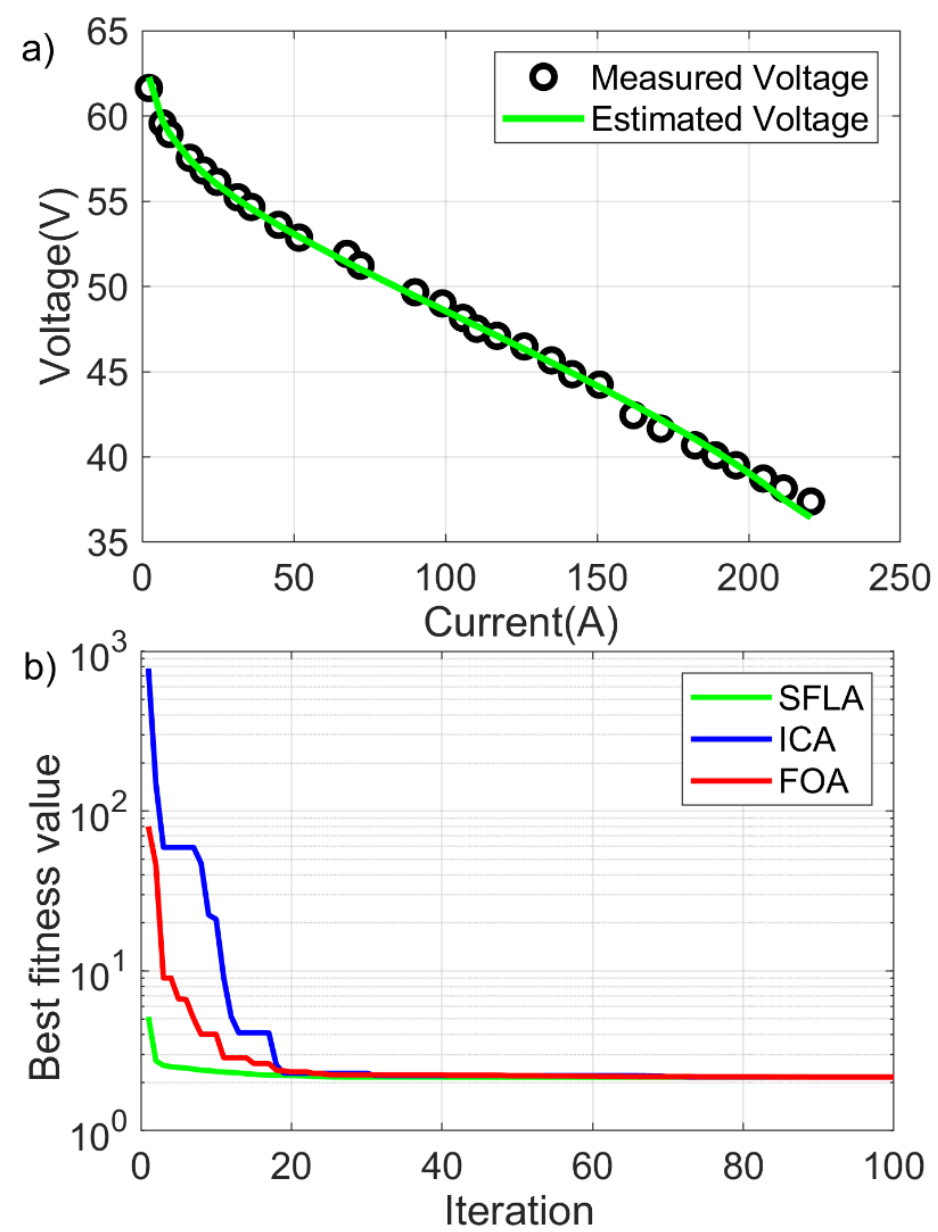

Figure 4: NedSstack PS6 PEMFC case study: a) estimated polarization curve by SFLA, b) fitness function (SSE) minimization trend comparison

\subsection{Case study 2 (BCS 500-W)}


The second case study of this manuscript investigates the polarization behavior of the BCS 500-W PEMFC stack produced by the American Company BCS Technologies. The characteristics of this FC, which have been collected from [32], are as follows: $N_{\text {cell }}=32, P_{H 2}=1 \mathrm{~atm}, P_{O 2}=0.2075 \mathrm{~atm}, T_{\text {stack }}=333 \mathrm{~K}, A=$ $64 \mathrm{~cm}^{2}, l=178 \mu \mathrm{m}$, and $J_{\max }=0.469 \mathrm{~A} \mathrm{~cm}^{-2}$. The maximum operating current of this system is $30.016 \mathrm{~A}$. Table 5 presents the estimated parameters and the best fitness achieved for BCS 500-W PEMFC stack by different algorithms. According to Table 5, the utilized algorithms have successfully extracted the suitable parameters for this case study. Moreover, compared to the available optimizers in the literature, some improvement in the minimum value of the defined fitness function can be observed. Table 5 also shows that SFLA has obtained the minimum value in terms of the defined fitness function. Figure 5a presents the estimated polarization curve by SFLA. The point-by-point current-voltage values achieved by all of the optimization methods are also reported in Table A.2 in the appendix. Figure 5b compares the minimization tend of different algorithms. As it is seen, ICA and SFLA converges faster than the FOA.

Table 5: The identified parameters and the corresponded fitness value

\begin{tabular}{ccccccc}
\hline Parameter & SFLA & ICA & FOA & SSO [30] & DEM [30] & GWO [32] \\
\hline$\xi_{1}$ & -0.965740 & -0.908643 & -0.992829 & -0.8532 & -0.948 & -1.0180 \\
$\xi_{2} \times 10^{-3}$ & 3.080 & 2.4798 & 2.621 & 4.8115 & 4.8115 & 2.3115 \\
$\xi_{3} \times 10^{-5}$ & 7.223600 & 4.4583194 & 3.746368 & 9.4334 & 7.6000 & 5.2400 \\
$\xi_{4} \times 10^{-5}$ & -19.3 & -19.3 & -19.3 & -19.205 & -19.300 & -12.815 \\
$R_{C}(\Omega) \times 10^{-4}$ & 1.00 & 2.46 & 1.00 & 3.499 & 3.000 & 7.504 \\
$\lambda$ & 20.88622 & 22.66264 & 21.101126 & 23 & 23 & 18.8547 \\
$\beta(\mathrm{V})$ & 0.016126 & 0.016238 & 0.016269 & 0.01589 & 0.0160 & 0.0136 \\
Best fitness & 0.011697 & 0.011856 & 0.011819 & 0.01219 & 0.01299 & 7.1889 \\
\hline
\end{tabular}



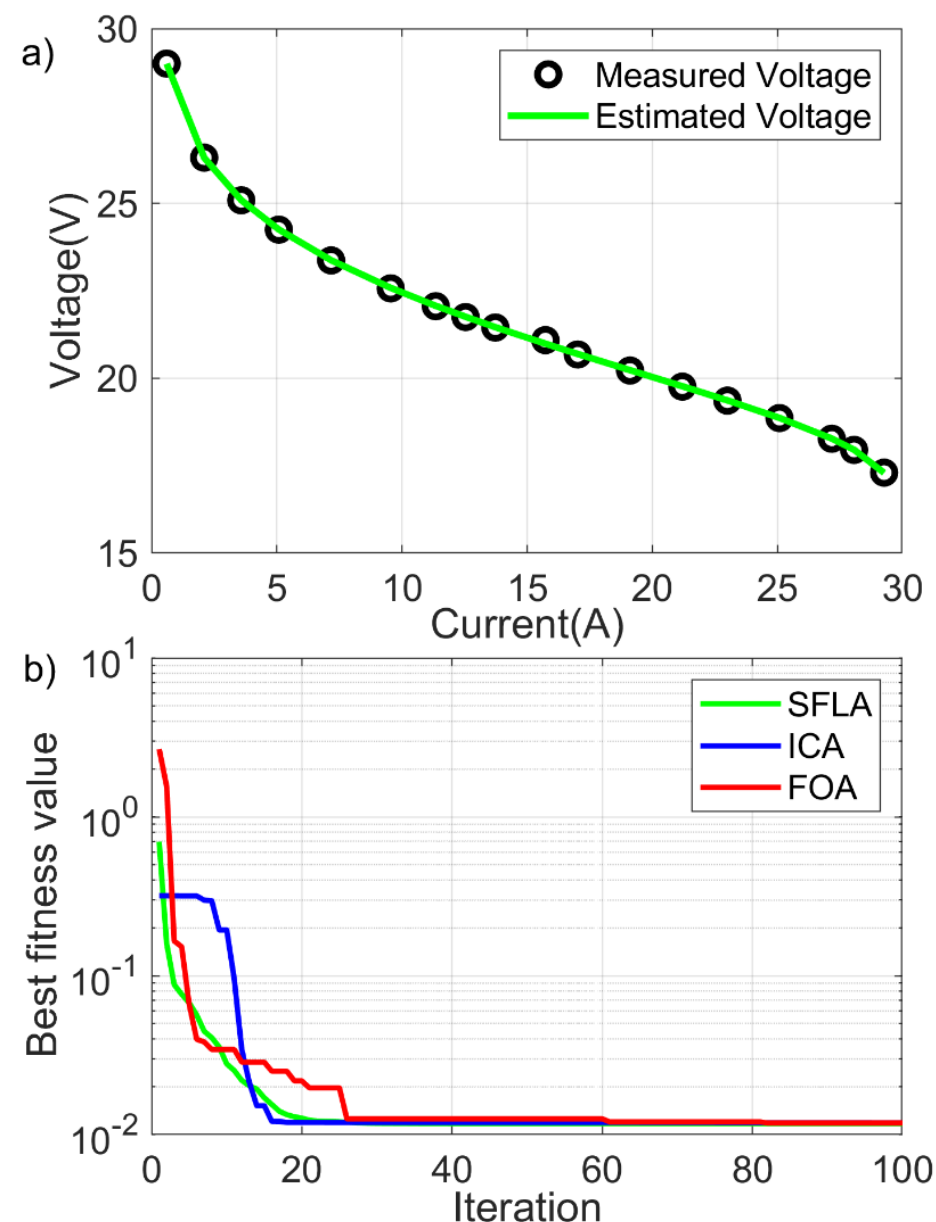

Figure 5: BCS 500-W PEMFC case study: a) estimated polarization curve by SFLA, b) fitness function (SSE) minimization trend comparison

\subsection{Algorithm selection}

In fact, all the three utilized algorithms in this manuscript have already shown a great potential for solving different engineering problems. So far, it has been observed that these algorithms are able to improve the defined best fitness value of this work (SSE between the measured and estimated voltage) compared to other available optimizers in the literature. Realized by the performed comparative study of the standard form of these algorithms in this work, it can be stated that ICA and FOA algorithms are more prone to premature convergence than SFLA, as shown in Figure 4b and Figure 5b. This is mainly due to the fact that SFLA combines the merits of genetic-based memetic and social behavior-based algorithms. It executes concurrently an independent local search inside each memeplex, and the entire frogs are then shuffled and 
reorganized into new memeplexes after a predefined number of local iterations to ensure global exploration. Concerning the FOA, one of the reasons for its premature convergence is the dependency of the updates on the current performance and not having a knowledge of the preceding best solutions. To alleviate this drawback, a new updating strategy can be formulated for FOA in future and the random and attraction movement parameters can be modified. Regarding the ICA, its performance can be improved by paying more attentions to the tuning parameters, which are more critical than the ones in other optimizers, especially the deviation parameter of the assimilation process. This parameter has a direct impact on achieving a balance between local and global explorations.

Another noteworthy aspect is that the performance of these algorithms is based on randomness and the sole best fitness value (SSE) in one of the runs cannot assure the acceptable performance of the optimization algorithm. As mentioned earlier, the listed values in Table 4 and Table 5 belong to the best solution found out of 100 independent runs, and there is no guarantee that the algorithms can repeat the same results. In this regard, some statistical measures, namely best, worst, variance, and standard deviation, are calculated by using the obtained best fitness values through each of the independent runs to show the robustness and probability of finding the optimal answer by the algorithms. These statistical factors are listed in Table 6 . Variance value shows how far a set of numbers are from their mean value and in this case the lesser the variance the better. Standard deviation also specifies the scattering of the data and a low value for this measure means the data tends to be closer to the average of the set. Table 6 includes the results of the mentioned statistical measures for SSO algorithm, in addition to SFLA, FOA, and ICA. This is because SSO has already shown a very good performance from itself over 100 independent runs. Moreover, the required data for calculating all the measures for this algorithm are available in [30]. According to Table 6, SFLA has achieved the lowest value in terms of variance and standard deviation compared to other algorithms. However, neither ICA nor FOA could achieve a better result than SSO. This superior performance of SFLA justifies the previously discussed advantages of this algorithm regarding the simultaneous local and global exploration. In this respect, SFLA algorithm is selected to be used for the 
optimization of the 500-W Horizon PEMFC, which is a new case study introduced in this work. It should be noted that this selection has been made based on the defined comparison criteria and utilized controlling parameters and it does not mean that the other two introduced algorithms are not suitable for parameters estimation of a PEMFC model. In fact, all the three algorithms are able to predict the PEMFC polarization curve with good accuracy. However, SFLA shows more robustness than the others do in the investigated cases.

Table 6: Statistical measures comparison

\begin{tabular}{|c|c|c|c|c|c|}
\hline Case study & $\begin{array}{l}\text { Computed } \\
\text { factor }\end{array}$ & SFLA & ICA & FOA & SSO [30] \\
\hline \multirow{4}{*}{1} & Best & 2.167055 & 2.168339 & 2.167091 & 2.18067 \\
\hline & Worst & 2.167598 & 2.518191 & 2.614219 & 2.25060 \\
\hline & Variance & $1.06829 \times 10^{-8}$ & 0.005940 & 0.016838 & $4.131 \times 10^{-4}$ \\
\hline & $\begin{array}{l}\text { Standard } \\
\text { deviation }\end{array}$ & $1.03358 \times 10^{-4}$ & 0.077072 & 0.129763 & 0.0203 \\
\hline \multirow{4}{*}{2} & Best & 0.011697 & 0.011856 & 0.011819 & 0.01219 \\
\hline & Worst & 0.011698 & 0.034665 & 0.030233 & 0.01520 \\
\hline & Variance & $2.53971 \times 10^{-15}$ & $3.43806 \times 10^{-5}$ & $1.74131 \times 10^{-5}$ & $7.588 \times 10^{-7}$ \\
\hline & $\begin{array}{l}\text { Standard } \\
\text { deviation }\end{array}$ & $5.03955 \times 10^{-8}$ & 0.005863 & 0.004172 & $8.711 \times 10^{-4}$ \\
\hline
\end{tabular}

\subsection{Case study 3 (500-W Horizon PEMFC)}

The last case study of this work, which is the main focus of this manuscript, is for an open cathode 500-W Horizon PEMFC. In order to collect justifiable experimental data and provide the required measurements for extracting the PEMFC model parameters, an experimental set-up has been developed as explained in details in section 4.4.1. Moreover, the obtained results regarding the performance verification of the SFLA algorithm as well as the tuned semi-empirical model are presented in section 4.4.2.

\subsubsection{Materials and methods}

The required data for the proposed new case study has been recorded from a developed test bench, shown in Figure 6, in Hydrogen Research Institute of Université du Québec à Trois-Rivières with a standard protocol. This test bench is used to test and validate the SFLA algorithm and the extracted PEMFC model. 
The set-up is mainly composed of a Horizon open-cathode PEMFC with a rated power of $500 \mathrm{~W}$. The PEMFC characteristics, gathered from [54] and the manufacture manual, are presented in Table 7. This PEMFC is self-humidified, air-cooled, and known as open-cathode or air breathing. It has two axial fans to provide the cathode with air and to cool down the stack. The flow rate of air supplied to the cathode side is controlled by the duty cycle of the fan which is strongly reliant on the requested power from the PEMFC and the stack temperature. In the anode side, the PEMFC is equipped with an inlet and an outlet valve. The inlet valve is utilized to feed the PEMFC with dry hydrogen. The hydrogen flow rate changes between 0 and $11.67 \times 10^{-2} \mathrm{Ls}^{-1}$ depending on the drawn power from the stack. The outlet valve is responsible for purging the accumulated water and nitrogen every $10 \mathrm{~s}$ for a duration of $10 \mathrm{~ms}$ to refill the anode with fresh hydrogen during the PEMFC operation. The exhaust flow of hydrogen after the purge rests on the difference of pressure between the environment $(1 \mathrm{~atm})$ and the anode side $(1.48 \mathrm{~atm}$ as suggested by the manufacturer). Furthermore, the pressure difference between the anode and the cathode sides must not surpass $0.493 \mathrm{~atm}$ to prevent the membrane from being damaged. The control of the purge valve, fan speed, and hydrogen valve are performed through the PEMFC controller, and the acquisition of data (temperature, current, and voltage) are done by an embedded computer (National Instrument CompactRIO 9022). A programmable load manufactured by BK Precision with a maximum power of $1200 \mathrm{~W}$ is connected to the PEMFC in order to request different power profiles form the stack. The communication between the CompactRIO and the PC is via Ethernet connection every $100 \mathrm{~ms}$. The measured data (temperature, current, and voltage) from the real PEMFC is transferred to the PC by means of the CompactRIO and is used in the PEMFC model verification process.

Table 7: The characteristics of the Horizon 500-W open cathode PEMFC

\begin{tabular}{cc}
\hline \multicolumn{2}{c}{ Technical specification } \\
\hline Type of FC & PEM \\
Rated Power & $500 \mathrm{~W}$ \\
Rated performance & $22 \mathrm{~V} \mathrm{@} \mathrm{23.5} \mathrm{A}$ \\
Max Current & $42 \mathrm{~A}$ \\
Rated H2consumption & $7 \mathrm{SLPM}$ \\
Ambient temperature & 5 to $30^{\circ} \mathrm{C}$ \\
Max stack temperature & $65^{\circ} \mathrm{C}$
\end{tabular}




\begin{tabular}{cc} 
Cooling & Air (integrated cooling fan) \\
Reactants & Hydrogen and Air \\
$N_{\text {cell }}$ & 36 \\
$P_{H 2}$ & $0.55 \mathrm{~atm}$ \\
$P_{O 2}$ & $1 \mathrm{~atm}$ \\
$A$ & $52 \mathrm{~cm}^{2}$ \\
$l$ & $25 \mu \mathrm{m}$ \\
$J_{\max }$ & $0.446 \mathrm{~A} \mathrm{~cm}^{-2}$ \\
\hline
\end{tabular}

It should be noted that in this new case study the temperature is variable as opposed to other available case studies in the literature. The voltage-current curve of this PEMFC has been obtained by drawing a fixed current from the FC and measuring its output voltage. By slowly stepping up the load, the FC voltage response can be seen and recorded. After each increase in the current level, 15 to 25 minutes have been allowed to the FC to reach equilibrium. As opposed to the other two case studies in which the temperature is constant, this FC system reaches one stable temperature for each current level. It means that for each current level, there is one corresponded voltage and temperature measurement. All the tests have been conducted in a stable environment in the test center of Hydrogen Research Institute to maintain the conditions. Another point which needs to be mentioned is that the actual rated power of the utilized PEMFC in this work is $430 \mathrm{~W}$ with a maximum current of $25 \mathrm{~A}$. In fact, the rated power of this PEMFC has decreased over time due to degradation. 


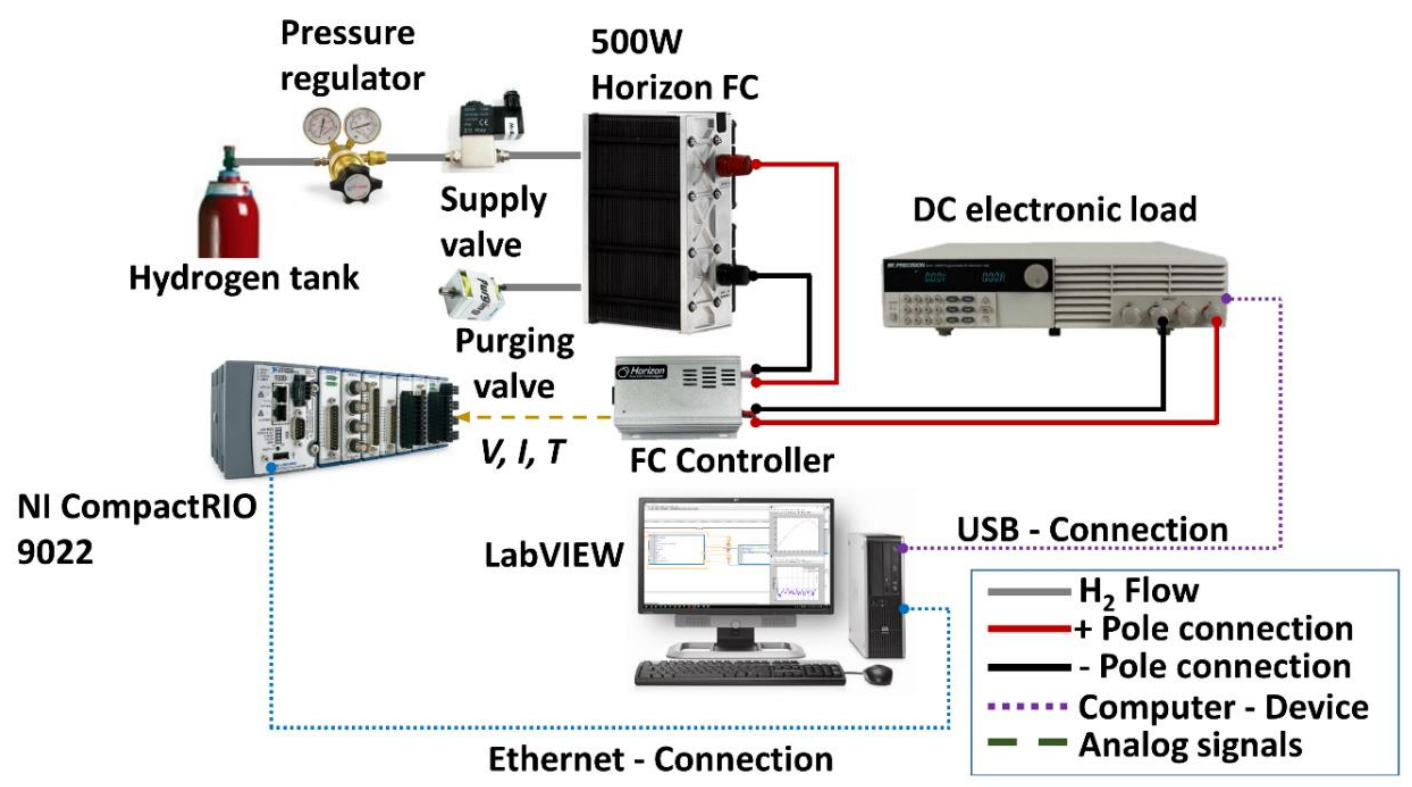

Figure 6: The developed test bench in Hydrogen Research Institute

\subsubsection{Experimental Results}

Table 8 presents the identified values for each unknown parameter after using the SFLA for parameter extraction. This table also shows the best fitness value achieved by using the identified parameters.

Table 8: The identified parameters and the obtained fitness value for 500-W Horizon PEMFC

\begin{tabular}{cc}
\hline Parameter & Estimated value by SFLA \\
\hline$\xi_{1}$ & -0.853200 \\
$\xi_{2} \times 10^{-3}$ & 2.522 \\
$\xi_{3} \times 10^{-5}$ & 7.843743 \\
$\xi_{4} \times 10^{-5}$ & -16.3 \\
$R_{C}(\Omega) \times 10^{-4}$ & 7.999 \\
$\lambda$ & 13 \\
$\beta(\mathrm{V})$ & 0.048869 \\
Best fitness & 0.015622 \\
\hline
\end{tabular}

The polarization characteristics of the 500-W Horizon PEMFC stack are reported point by point in Table 9 and shown in Figure 7a. The minimization trend of the fitness function is represented in Figure 7b. It can be seen that the stable value is achieved after almost 10 iterations. 
a)
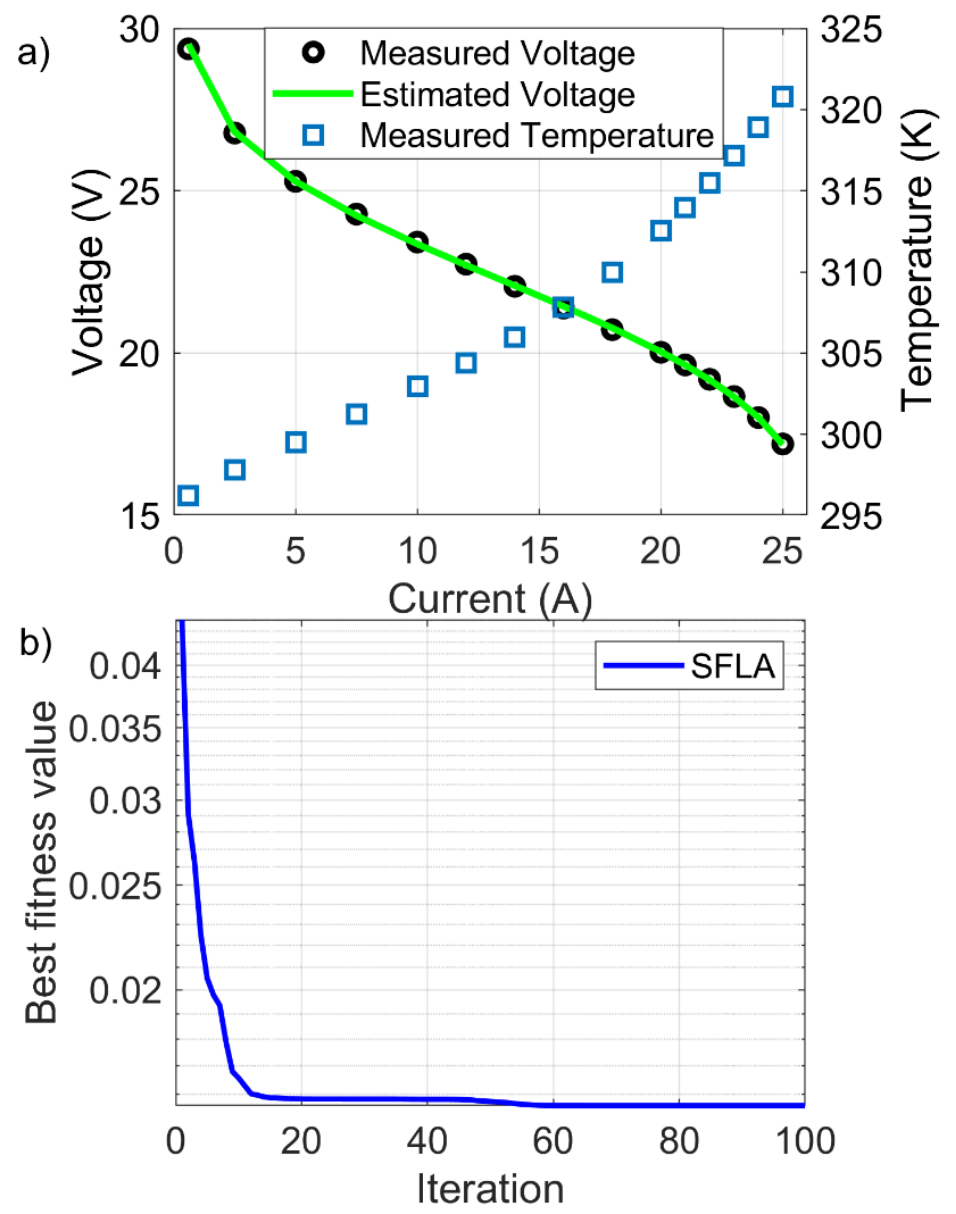

Figure 7: 500-W Horizon PEMFC case study: a) estimated polarization curve by SFLA, b) fitness function (SSE) minimization trend comparison

Table 9: The steady-state characteristics of the 500-W Horizon PEMFC

\begin{tabular}{ccccc}
\hline Current $(\mathrm{A})$ & $V_{F C, \text { meas }}(\mathrm{V})$ & $V_{F C, \text { est }}(\mathrm{SFLA})$ & $\mid$ Residual & Temperature $(\mathrm{K})$ \\
\hline 0.6 & 29.370000 & 29.514760 & 0.144759 & 296.200000 \\
2.5 & 26.777390 & 26.813765 & 0.036374 & 297.810917 \\
5 & 25.290250 & 25.287802 & 0.002448 & 299.520062 \\
7.5 & 24.281859 & 24.235411 & 0.046448 & 301.227449 \\
10 & 23.418000 & 23.356632 & 0.061367 & 302.950000 \\
12 & 22.739103 & 22.709020 & 0.030083 & 304.404279 \\
14 & 22.058523 & 22.078801 & 0.020277 & 306.006926 \\
16 & 21.386148 & 21.442688 & 0.056540 & 307.842680 \\
18 & 20.721728 & 20.775549 & 0.053821 & 309.994399 \\
20 & 20.026000 & 20.041864 & 0.015864 & 312.532000 \\
21 & 19.636350 & 19.632033 & 0.004317 & 313.961094 \\
22 & 19.191807 & 19.176821 & 0.014986 & 315.501399 \\
23 & 18.663630 & 18.653590 & 0.010040 & 317.153087 \\
24 & 18.015227 & 18.020263 & 0.005036 & 318.913454 \\
25 & 17.201250 & 17.182838 & 0.018412 & 320.776562 \\
\hline
\end{tabular}


In order to assess the probability of achiving a satisfactory fitness values, the previous defined statistical measures are calculated for this new case study. Figure 8 presents the histogram of the obtained best fitness value over 100 independent runs. The statistical measures are also reported in this figure to clarify the histogram plot. As it can be seen in this histogram, the frequency of obtaining the best fitness value is strikingly high by SFLA ensuring the reliablity of this metaheuristic algorithm. Figure 9 presents the simulated performance analysis of the 500-W Horizon PEMFC over various partial pressures of hydrogen in the anode side $\left(P_{\mathrm{H} 2}\right)$. Since this FC is an open cathode PEMFC, the pressure in the cathode side $\left(P_{\mathrm{O} 2}\right)$ is always $1 \mathrm{~atm}$. As is obsereved in Figure 9, regulating the pressure under $0.55 \mathrm{~atm}$ can results in less output power by the PEMFC. While setting a value more than 0.55 atm can increse the output power to some extent.

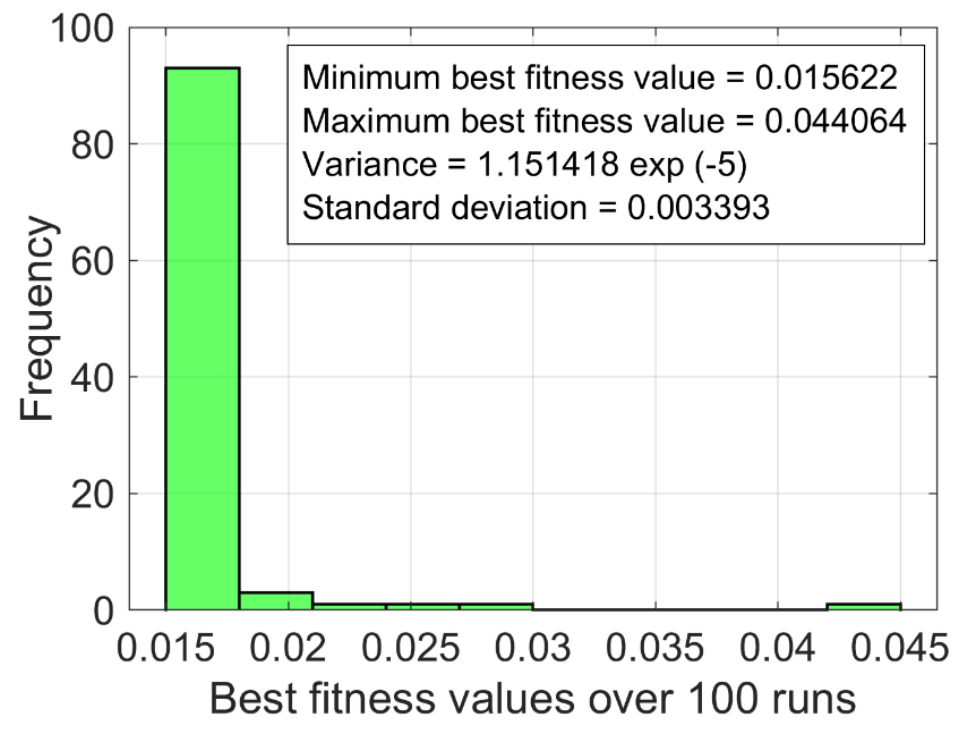

Figure 8: The histogram analysis of SFLA 


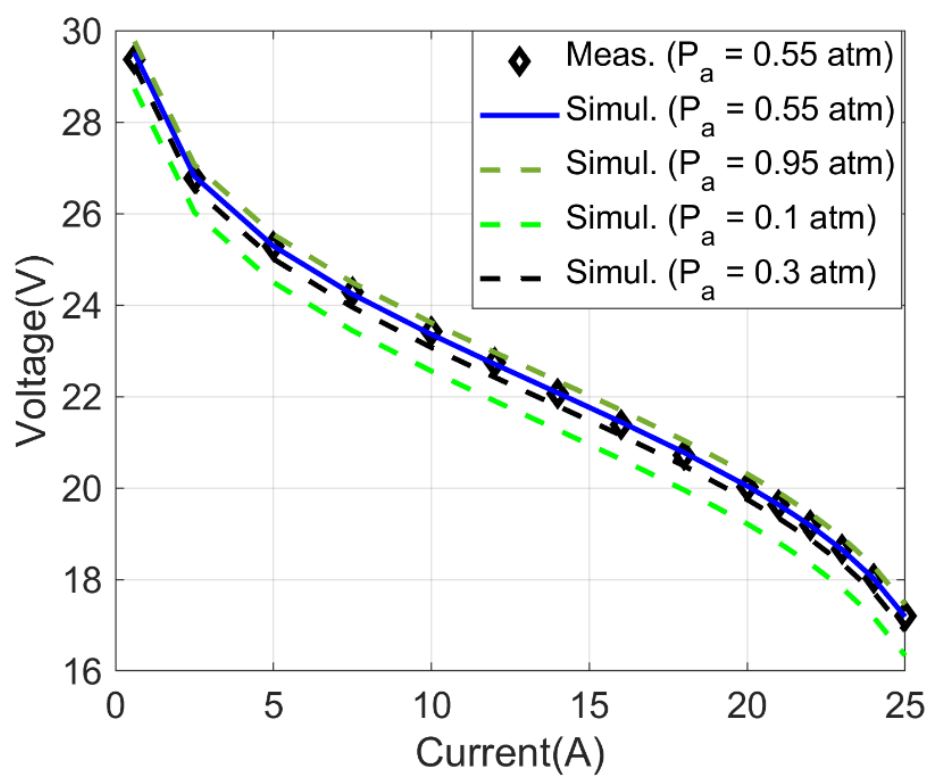

Figure 9: Polarization behaviour analysis in different partial pressures of hydrogen

To further evaluate the performance of the tuned PEMFC model by the SFLA algorithm, the presented current profile in Figure 10a has been applied to the Horizon PEMFC on the develped test bench and its stack temperature and voltage signals have been recorded. Subsequently, the same current profile has been imposed to the PEMFC model and its voltage estimation is compared with the measured one in Figure $10 \mathrm{~b}$. According to this figure, the tuned PEMFC model is able to imitate the output voltage of the real PEMFC satisfactorily. It should be noted that the PEMFC model is fed with the measred temperature, shown in Figure 10a, to predict the output voltage. 

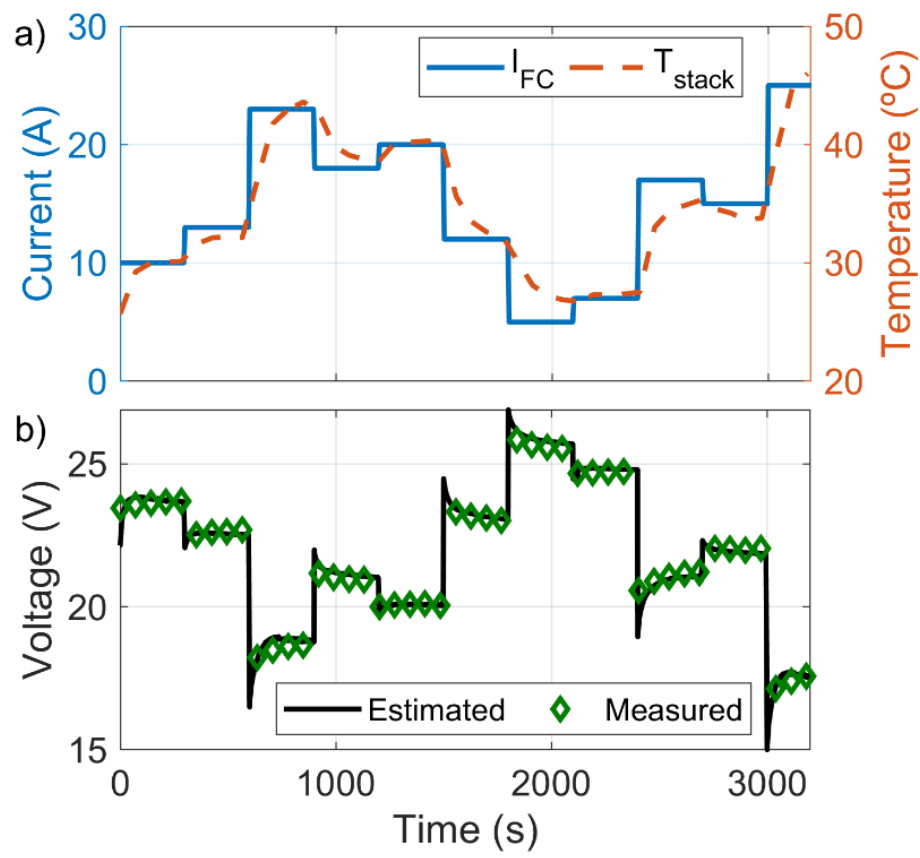

Figure 10: Performance validation of the tuned PEMFC model for the Horizon 500-W PEMFC case study: a) the current profile applied to the real PEMFC and the corresponding measured temperature, and $b$ ) the comparison of the estimated and measured voltage.

\section{Conclusion}

This paper investigates the performance of three metaheuristic optimization algorithms, namely SFLA, ICA, and FOA, in a PEMFC parameter extraction problem. In this regard, the performance comparison of the algorithms is performed by using the SSE between the measured and estimated PEMFC voltage as the fitness function for two available case studies in the literature over 100 independent runs. Subsequently, the precision of the algorithms is judged based on their achieved best fitness value, worst fitness value, variance, and standard deviation. Finally, the selected algorithm from the comparison step is used to identify the parameters of the PEMFC model for a new case study, a 500-W Horizon PEMFC, provided by this work. This new case study is an open cathode PEMFC and has variable temperature as opposed to the other existing case studies in the literature. The final results of this work indicate that with regard to the best SSE, SFLA slightly outperforms ICA and FOA in both case studies. However, the obtained worst SSEs show that SFLA performs $20 \%$ better than ICA and two times better than FOA in the first and second case studies. 
Moreover, the attained variance and standard deviation of SFLA are noticeably less than the other algorithms which are the justification of accuracy and repeatability of this method. The results of this paper opens up the following avenues for future researches:

- Utilizing the selected optimization algorithm of this work in dynamic PEMFC model calibration.

- Investigating the performance of new optimization algorithms by using the provided case study of this research.

- Using the proposed metaheuristic optimization algorithms for a more complete PEMFC model including hydrogen consumption prediction.

\section{Acknowledgements}

This work was supported in part by the Natural Sciences and Engineering Research Council of Canada (NSERC), the Fonds de recherche du Québec-Nature et technologies (FRQNT), and Canada Research Chairs program.

\section{Nomenclature}

Variables

$\begin{array}{cl}V_{F C} & \text { Output voltage of the PEMFC, } \mathrm{V} \\ E_{\text {Nernst }} & \text { Sum of cell reversible voltage, } \mathrm{V} \\ V_{\text {Act }} & \text { Activation voltage, } \mathrm{V} \\ V_{\text {Ohmic }} & \text { Ohmic voltage, } \mathrm{V} \\ V_{\text {Con }} & \text { Concentration voltage, } \mathrm{V} \\ N_{\text {cell }} & \text { Number of cells } \\ T_{\text {stack }} & \text { Stack temperature, } \mathrm{K} \\ P_{\mathrm{H} 2} & \text { Hydrogen partial pressure in anode side, atm } \\ P_{O 2} & \text { Oxygen partial pressure in cathode side, atm } \\ R H_{C} & \text { Relative humidity of vapor in the cathode, \% } \\ R H_{a} & \text { Relative humidity of vapor in the anode, } \% \\ P_{C} & \text { Cathode inlet pressures, atm } \\ P_{a} & \text { Anode inlet pressures, atm } \\ I_{F C} & \text { FC operating current, A } \\ A & \text { Active area of the membrane, } \mathrm{cm}^{2} \\ P_{H_{2} O}^{s a t} & \text { Saturation water pressure, atm } \\ \xi_{k} & \text { Semi-empirical coefficients } \\ C o_{2} & \text { Oxygen concentration, mol } \mathrm{cm}^{-3} \\ & \end{array}$




\begin{tabular}{|c|c|}
\hline$R_{m}$ & Membrane resistance, $\Omega$ \\
\hline$R_{C}$ & Equivalent contact resistance to electron conduction, $\Omega$ \\
\hline$\rho_{m}$ & Resistivity of the membrane, $\Omega \mathrm{cm}$ \\
\hline$l$ & Membrane thickness, cm \\
\hline$J$ & Actual current density, $\mathrm{A} \mathrm{cm}^{-2}$ \\
\hline$\lambda$ & Adaptable parameter related to the water content of the membrane \\
\hline$\beta$ & Parametric coefficient \\
\hline$J_{\max }$ & Maximum current density, $\mathrm{A} \mathrm{cm}^{-2}$ \\
\hline$V_{F C, \text { meas }}$ & Measured output voltage, $\mathrm{V}$ \\
\hline$V_{F C, e s t}$ & Estimated output voltage by the model, V \\
\hline$N$ & Number of sample data \\
\hline$P$ & Initial population \\
\hline$X_{i}$ & Individual frog solution \\
\hline$m$ & Memplexe \\
\hline$n$ & Number of frog per memplex \\
\hline$X_{b}$ & Best frog solution \\
\hline$X_{w}$ & Worst frog solution \\
\hline$X_{g}$ & Global best frog solution \\
\hline$D_{i}$ & Frog position change \\
\hline$X_{w, n e w}$ & New position of the frog with the worst fitness \\
\hline$X_{w, p r e s e n t}$ & Current position of the frog \\
\hline$D_{\max }$ & Maximum possible variation in the position of a frog \\
\hline$p_{N_{\text {var }}}$ & Countries containing the optimization problem variables \\
\hline$N_{\text {var }}$ & Dimension of the problem \\
\hline$C_{n}$ & $N$ th imperialist normalized cost \\
\hline$c_{n}$ & $N$ th imperialist cost \\
\hline$p_{n}$ & Normalized power of each imperialist \\
\hline$N_{i m p}$ & Number of imperialists \\
\hline$N C_{n}$ & $N$ th empire initial number of colonies \\
\hline$N_{c o l}$ & Number of colonies \\
\hline$\sigma$ & Tuning parameter of ICA \\
\hline$d$ & Distance between colony and imperialist \\
\hline$\left\{V_{1}\right\}$ & Vector with unity length \\
\hline$\theta$ & Random number with uniform distribution \\
\hline$\gamma$ & Ratio of deviation from the original direction \\
\hline$T C_{n}$ & Total cost of the $n$th empire \\
\hline$\psi$ & Empirical forgetting factor of ICA \\
\hline$P_{n}$ & Possession probability \\
\hline$\omega(r)$ & Attractiveness \\
\hline$r$ & Distance between two fireflies \\
\hline$\omega_{0}$ & Initial attractiveness \\
\hline$\kappa$ & Fixed light absorption facto \\
\hline$d$ & Dimension of the problem \\
\hline$x_{i}$ & Positions of $i$ firefly \\
\hline$\alpha$ & Tuning parameter of FOA \\
\hline
\end{tabular}




$\begin{array}{ll}\text { Abbreviations } & \\ \text { SFLA } & \text { Shuffled Frog-Leaping Algorithm } \\ \text { FOA } & \text { Firefly Optimization Algorithm } \\ \text { ICA } & \text { Imperialist Competitive Algorithm } \\ \text { SSE } & \text { Sum Square Error } \\ \text { PEMFC } & \text { proton exchange membrane fuel cell } \\ \text { FC } & \text { Fuel Cell } \\ \text { CS-EO } & \text { Cuckoo search algorithm with explosion operator } \\ \text { SSO } & \text { Slap swarm optimizer } \\ \text { GHO } & \text { Grasshopper optimization } \\ \text { GWO } & \text { Grey wolf optimizer } \\ \text { AC-POA } & \text { Aging and challenging P systems based optimization algorithm } \\ \text { TLBO-DE } & \text { Hybrid teaching learning based optimization - differential evolution } \\ \text { GRG } & \text { Generalized reduced gradient } \\ \text { HADE } & \text { Hybrid adaptive differential evolution } \\ \text { GA } & \text { Genetic algorithm } \\ \text { TRADE } & \text { Transferred adaptive differential evolution } \\ \text { STLBO } & \text { Simplified teaching-learning based optimization } \\ \text { ADE } & \text { Adaptive differential evolution } \\ \text { DEM } & \text { dynamic electrochemical model }\end{array}$

\section{Appendix}

Figure A.1 and Figure A.2 present the measured and estimated polarization curves for NedSstack PS6 and BCS 500-W respectively. Moreover, Table A.1 and Table A.2 provide the point-by-point data regarding the current-voltage characteristics of the NedSstack PS6 and BCS 500-W respectively in different scenarios.

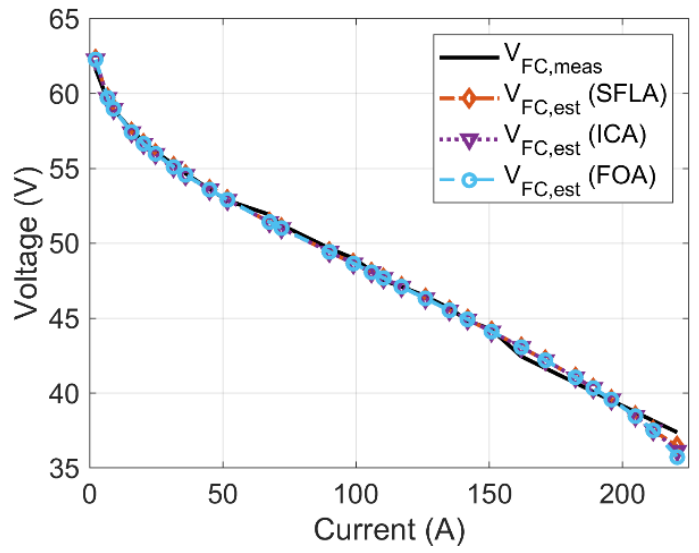

Figure A.1: Estimated polarization curves by different algorithms in case study 1 (NedSstack PS6) 


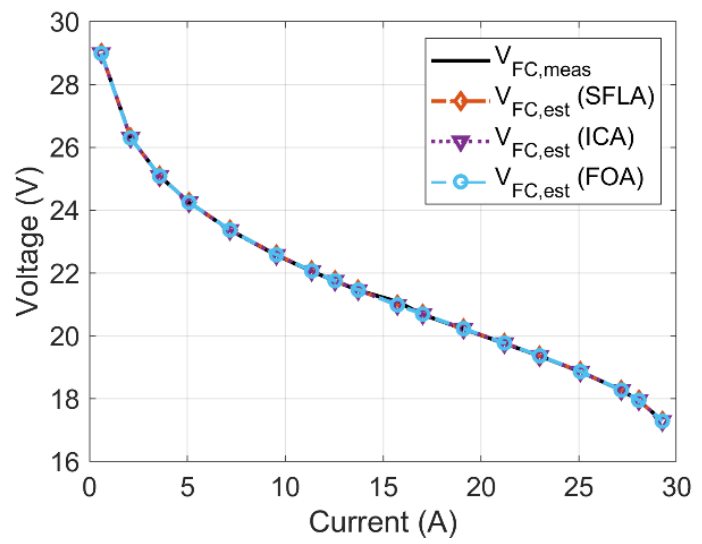

Figure A.2: Estimated polarization curves by different algorithms in case study 2 (BCS 500-W)

Table A.1: Estimated voltage for each current level (case study 1)

\begin{tabular}{ccccc}
\hline Current $(\mathrm{A})$ & $V_{F C, \text { meas }}(\mathrm{V})$ & $V_{F C, \text { est }}(\mathrm{SFLA})$ & $V_{F C, \text { est }}(\mathrm{ICA})$ & $V_{F C, \text { est }}(\mathrm{FOA})$ \\
\hline 2.25 & 61.64 & 62.274793 & 62.266538 & 62.274723 \\
6.75 & 59.57 & 59.702854 & 59.694581 & 59.702843 \\
9 & 58.94 & 58.972628 & 58.964351 & 58.972646 \\
15.75 & 57.54 & 57.424395 & 57.416125 & 57.424500 \\
20.25 & 56.8 & 56.648715 & 56.640467 & 56.648877 \\
24.75 & 56.13 & 55.978682 & 55.970471 & 55.978901 \\
31.5 & 55.23 & 55.096910 & 55.088779 & 55.097213 \\
36 & 54.66 & 54.564243 & 54.556183 & 54.564601 \\
45 & 53.61 & 53.585377 & 53.577508 & 53.585843 \\
51.75 & 52.86 & 52.903552 & 52.895867 & 52.904098 \\
67.5 & 51.91 & 51.418171 & 51.411066 & 51.418897 \\
72 & 51.22 & 51.011656 & 51.004757 & 51.012432 \\
90 & 49.66 & 49.428950 & 49.423070 & 49.429917 \\
99 & 49 & 48.651772 & 48.646526 & 48.652829 \\
105.8 & 48.15 & 48.066470 & 48.061764 & 48.067594 \\
110.3 & 47.52 & 47.679019 & 47.674699 & 47.680184 \\
117 & 47.1 & 47.100754 & 47.097055 & 47.101981 \\
126 & 46.48 & 46.318935 & 46.316158 & 46.320241 \\
135 & 45.66 & 45.528012 & 45.526266 & 45.529393 \\
141.8 & 44.85 & 44.922139 & 44.921248 & 44.923573 \\
150.8 & 44.24 & 44.106073 & 44.106419 & 44.107573 \\
162 & 42.45 & 43.061514 & 43.063578 & 43.063089 \\
171 & 41.66 & 42.191767 & 42.195365 & 42.193396 \\
182.3 & 40.68 & 41.047602 & 41.053336 & 41.049291 \\
189 & 40.09 & 40.331979 & 40.339095 & 40.333698 \\
195.8 & 39.51 & 39.565790 & 39.574404 & 39.567536 \\
204.8 & 38.73 & 38.457496 & 38.468245 & 38.459271 \\
211.5 & 38.15 & 37.507940 & 37.520399 & 37.509734 \\
220.5 & 37.38 & 36.442502 & 36.142308 & 35.725957 \\
\hline & & & &
\end{tabular}


Table A.2: Estimated voltage for each current level (case study 2)

\begin{tabular}{ccccc}
\hline Current $(\mathrm{A})$ & $V_{F C, \text { meas }}(\mathrm{V})$ & $V_{F C, \text { est }}(\mathrm{SFLA})$ & $V_{F C, \text { est }}(\mathrm{ICA})$ & $V_{F C, \text { est }}(\mathrm{FOA})$ \\
\hline 0.60 & 29 & 28.997223 & 29.001417 & 28.993084 \\
2.10 & 26.31 & 26.305937 & 26.307798 & 26.301435 \\
3.58 & 25.09 & 25.093555 & 25.094224 & 25.089256 \\
5.08 & 24.25 & 24.254620 & 24.254447 & 24.250678 \\
7.17 & 23.37 & 23.375416 & 23.374433 & 23.372080 \\
9.55 & 22.57 & 22.584615 & 22.583084 & 22.582041 \\
11.35 & 22.06 & 22.071327 & 22.069605 & 22.069350 \\
12.54 & 21.75 & 21.758463 & 21.756711 & 21.756882 \\
13.73 & 21.45 & 21.461262 & 21.459553 & 21.460072 \\
15.73 & 21.09 & 20.987741 & 20.986259 & 20.987190 \\
17.02 & 20.68 & 20.694509 & 20.693271 & 20.694346 \\
19.11 & 20.22 & 20.230985 & 20.230291 & 20.231390 \\
21.20 & 19.76 & 19.770943 & 19.770945 & 19.771789 \\
23 & 19.36 & 19.366024 & 19.366701 & 19.367081 \\
25.08 & 18.86 & 18.866466 & 18.867889 & 18.867407 \\
27.17 & 18.27 & 18.274720 & 18.276501 & 18.274690 \\
28.06 & 17.95 & 17.953310 & 17.954837 & 17.952238 \\
29.26 & 17.30 & 17.292877 & 17.292559 & 17.288378 \\
\hline
\end{tabular}




\section{References}

[1] S. K. Jha and H. Puppala, "Prospects of renewable energy sources in India: Prioritization of alternative sources in terms of Energy Index," Energy, vol. 127, pp. 116-127, 2017/05/15/ 2017.

[2] W. K. Al-Nassar, S. Neelamani, K. A. Al-Salem, and H. A. Al-Dashti, "Feasibility of offshore wind energy as an alternative source for the state of Kuwait," Energy, vol. 169, pp. 783-796, 2019/02/15/ 2019.

[3] D. Karamanev, V. Pupkevich, K. Penev, V. Glibin, J. Gohil, and V. Vajihinejad, "Biological conversion of hydrogen to electricity for energy storage," Energy, vol. 129, pp. 237-245, 2017/06/15/ 2017.

[4] M. Uzunoglu and M. S. Alam, "33 - Fuel-Cell Systems for Transportations A2 - Rashid, Muhammad $\mathrm{H}, "$ in Power Electronics Handbook (Fourth Edition), ed: Butterworth-Heinemann, 2018, pp. 10911112.

[5] A. K. Soltani, M. Kandidayeni, L. Boulon, and D. L. St-Pierre, "Modular Energy Systems in Vehicular Applications," Energy Procedia, vol. 162, pp. 14-23, 2019/04/01/ 2019.

[6] M. Blal, A. Benatiallah, A. NeÇaibia, S. Lachtar, N. Sahouane, and A. Belasri, "Contribution and investigation to compare models parameters of (PEMFC), comprehensives review of fuel cell models and their degradation," Energy, vol. 168, pp. 182-199, 2019/02/01/ 2019.

[7] S. L. Chavan and D. B. Talange, "Modeling and performance evaluation of PEM fuel cell by controlling its input parameters," Energy, vol. 138, pp. 437-445, 2017/11/01/ 2017.

[8] A. Macias, M. Kandidayeni, L. Boulon, and H. Chaoui, "A novel online energy management strategy for multi fuel cell systems," in 2018 IEEE International Conference on Industrial Technology (ICIT), 2018, pp. 2043-2048.

[9] M. Kandidayeni, A. Macias, A. A. Amamou, L. Boulon, and S. Kelouwani, "Comparative Analysis of Two Online Identification Algorithms in a Fuel Cell System," Fuel Cells, vol. 18, pp. 347-358, 2018.

[10] A. Amamou, M. Kandidayeni, L. Boulon, and S. Kelouwani, "Real time adaptive efficient cold start strategy for proton exchange membrane fuel cells," Applied Energy, vol. 216, pp. 21-30, 2018/04/15/ 2018.

[11] M. Kandidayeni, A. Macias, L. Boulon, and S. Kelouwani, "Optimized Fuzzy Thermal Management of an Open Cathode Fuel Cell System," in 2018 IEEE Vehicle Power and Propulsion Conference (VPPC), 2018, pp. 1-6.

[12] R. Petrone, Z. Zheng, D. Hissel, M. C. Péra, C. Pianese, M. Sorrentino, et al., "A review on modelbased diagnosis methodologies for PEMFCs," International Journal of Hydrogen Energy, vol. 38, pp. 7077-7091, 2013/06/10/ 2013.

[13] K. Ettihir, L. Boulon, M. Becherif, K. Agbossou, and H. S. Ramadan, "Online identification of semiempirical model parameters for PEMFCs," International Journal of Hydrogen Energy, vol. 39, pp. 21165-21176, 2014/12/12/ 2014.

[14] J. Wu, X. Z. Yuan, H. Wang, M. Blanco, J. J. Martin, and J. Zhang, "Diagnostic tools in PEM fuel cell research: Part I Electrochemical techniques," International Journal of Hydrogen Energy, vol. 33, pp. 1735-1746, 2008/03/01/ 2008.

[15] A. Saadi, M. Becherif, A. Aboubou, and M. Y. Ayad, "Comparison of proton exchange membrane fuel cell static models," Renewable Energy, vol. 56, pp. 64-71, 2013/08/01/ 2013.

[16] L. Boulon, D. Hissel, A. Bouscayrol, and M. Pera, "From Modeling to Control of a PEM Fuel Cell Using Energetic Macroscopic Representation," IEEE Transactions on Industrial Electronics, vol. 57, pp. 1882-1891, 2010.

[17] J. C. Amphlett, R. M. Baumert, R. F. Mann, B. A. Peppley, P. R. Roberge, and T. J. Harris, "Performance modeling of the Ballard Mark IV solid polymer electrolyte fuel cell. 1: Mechanistic 
model development," Journal of the Electrochemical Society; (United States), pp. Medium: X; Size: Pages: 1-8, 1995.

[18] M. Soltani and S. Mohammad Taghi Bathaee, "Development of an empirical dynamic model for a Nexa PEM fuel cell power module," Energy Conversion and Management, vol. 51, pp. 2492-2500, 2010/12/01/ 2010.

[19] M. Kandidayeni, A. Macias, A. A. Amamou, L. Boulon, S. Kelouwani, and H. Chaoui, "Overview and benchmark analysis of fuel cell parameters estimation for energy management purposes," Journal of Power Sources, vol. 380, pp. 92-104, 2018/03/15/ 2018.

[20] S. Yang and N. Wang, "A novel P systems based optimization algorithm for parameter estimation of proton exchange membrane fuel cell model," International Journal of Hydrogen Energy, vol. 37, pp. 8465-8476, 2012.

[21] U. K. Chakraborty, T. E. Abbott, and S. K. Das, "PEM fuel cell modeling using differential evolution," Energy, vol. 40, pp. 387-399, 2012.

[22] A. Askarzadeh and A. Rezazadeh, "An Innovative Global Harmony Search Algorithm for Parameter Identification of a PEM Fuel Cell Model," IEEE Transactions on Industrial Electronics, vol. 59, pp. 3473-3480, 2012.

[23] A. Sadollah, Y. Choi, and J. H. Kim, "Metaheuristic optimization algorithms for approximate solutions to ordinary differential equations," in 2015 IEEE Congress on Evolutionary Computation (CEC), 2015, pp. 792-798.

[24] S. Tripathi and M. A. Ikbal, "Optimization of LMS Algorithm for Adaptive Filtering using Global Optimization Techniques," International Journal of Computer Applications, vol. 132, pp. 09758887, 2015.

[25] S. Zhao and B. Huang, "On initialization of the Kalman filter," in 20176 th International Symposium on Advanced Control of Industrial Processes (AdCONIP), 2017, pp. 565-570.

[26] K. Priya, K. Sathishkumar, and N. Rajasekar, "A comprehensive review on parameter estimation techniques for Proton Exchange Membrane fuel cell modelling," Renewable and Sustainable Energy Reviews, vol. 93, pp. 121-144, 2018/10/01/ 2018.

[27] Z.-J. Mo, X.-J. Zhu, L.-Y. Wei, and G.-Y. Cao, "Parameter optimization for a PEMFC model with a hybrid genetic algorithm," International Journal of Energy Research, vol. 30, pp. 585-597, 2006.

[28] S. Xu, Y. Wang, and Z. Wang, "Parameter estimation of proton exchange membrane fuel cells using eagle strategy based on JAYA algorithm and Nelder-Mead simplex method," Energy, vol. 173, pp. 457-467, 2019/04/15/ 2019.

[29] Y. Chen and N. Wang, "Cuckoo search algorithm with explosion operator for modeling proton exchange membrane fuel cells," International Journal of Hydrogen Energy, vol. 44, pp. 3075-3087, 2019/01/28/2019.

[30] A. A. El-Fergany, "Extracting optimal parameters of PEM fuel cells using Salp Swarm Optimizer," Renewable Energy, vol. 119, pp. 641-648, 2018.

[31] A. A. El-Fergany, "Electrical characterisation of proton exchange membrane fuel cells stack using grasshopper optimiser," IET Renewable Power Generation, vol. 12, pp. 9-17, 2018.

[32] M. Ali, M. A. El-Hameed, and M. A. Farahat, "Effective parameters' identification for polymer electrolyte membrane fuel cell models using grey wolf optimizer," Renewable Energy, vol. 111, pp. 455-462, 2017/10/01/ 2017.

[33] S. Yang, R. Chellali, X. Lu, L. Li, and C. Bo, "Modeling and optimization for proton exchange membrane fuel cell stack using aging and challenging P systems based optimization algorithm," Energy, vol. 109, pp. 569-577, 2016.

[34] O. E. Turgut and M. T. Coban, "Optimal proton exchange membrane fuel cell modelling based on hybrid Teaching Learning Based Optimization - Differential Evolution algorithm," Ain Shams Engineering Journal, vol. 7, pp. 347-360, 2016. 
[35] Z. W. Geem and J. S. Noh, "Parameter Estimation for a Proton Exchange Membrane Fuel Cell Model Using GRG Technique," Fuel Cells, vol. 16, pp. 640-645, 2016.

[36] Z. Sun, N. Wang, Y. Bi, and D. Srinivasan, "Parameter identification of PEMFC model based on hybrid adaptive differential evolution algorithm," Energy, vol. 90, pp. 1334-1341, 2015.

[37] C. Restrepo, T. Konjedic, A. Garces, J. Calvente, and R. Giral, "Identification of a Proton-Exchange Membrane Fuel Cell's Model Parameters by Means of an Evolution Strategy," IEEE Transactions on Industrial Informatics, vol. 11, pp. 548-559, 2015.

[38] N. Rajasekar, B. Jacob, K. Balasubramanian, K. Priya, K. Sangeetha, and T. Sudhakar Babu, "Comparative study of PEM fuel cell parameter extraction using Genetic Algorithm," Ain Shams Engineering Journal, vol. 6, pp. 1187-1194, 2015.

[39] K. Priya, T. Sudhakar Babu, K. Balasubramanian, K. Sathish Kumar, and N. Rajasekar, "A novel approach for fuel cell parameter estimation using simple Genetic Algorithm," Sustainable Energy Technologies and Assessments, vol. 12, pp. 46-52, 2015.

[40] W. Gong, X. Yan, X. Liu, and Z. Cai, "Parameter extraction of different fuel cell models with transferred adaptive differential evolution," Energy, vol. 86, pp. 139-151, 2015.

[41] Q. Niu, H. Zhang, and K. Li, "An improved TLBO with elite strategy for parameters identification of PEM fuel cell and solar cell models," International Journal of Hydrogen Energy, vol. 39, pp. 38373854, 2014.

[42] W. Gong and Z. Cai, "Parameter optimization of PEMFC model with improved multi-strategy adaptive differential evolution," Engineering Applications of Artificial Intelligence, vol. 27, pp. 2840, 2014.

[43] J. Cheng and G. Zhang, "Parameter fitting of PEMFC models based on adaptive differential evolution," International Journal of Electrical Power \& Energy Systems, vol. 62, pp. 189-198, 2014.

[44] R. F. Mann, J. C. Amphlett, M. A. I. Hooper, H. M. Jensen, B. A. Peppley, and P. R. Roberge, "Development and application of a generalised steady-state electrochemical model for a PEM fuel cell," Journal of Power Sources, vol. 86, pp. 173-180, 2000/03/01/ 2000.

[45] T. V. Nguyen and R. E. White, "A Water and Heat Management Model for Proton-ExchangeMembrane Fuel Cells," Journal of The Electrochemical Society, vol. 140, pp. 2178-2186, August 1, 19931993.

[46] S. M. R. Niya and M. Hoorfar, "Determination of Activation Losses in Proton Exchange Membrane Fuel Cells," p. V001T06A002, 2014.

[47] M. J. Khan and M. T. Iqbal, "Modelling and Analysis of Electro-chemical, Thermal, and Reactant Flow Dynamics for a PEM Fuel Cell System," Fuel Cells, vol. 5, pp. 463-475, 2005.

[48] J. M. Correa, F. A. Farret, L. N. Canha, and M. G. Simoes, "An electrochemical-based fuel-cell model suitable for electrical engineering automation approach," IEEE Transactions on Industrial Electronics, vol. 51, pp. 1103-1112, 2004.

[49] H. Garg, "A hybrid PSO-GA algorithm for constrained optimization problems," Applied Mathematics and Computation, vol. 274, pp. 292-305, 2016/02/01/2016.

[50] M. Eusuff, K. Lansey, and F. Pasha, "Shuffled frog-leaping algorithm: a memetic meta-heuristic for discrete optimization," Engineering Optimization, vol. 38, pp. 129-154, 2006/03/01 2006.

[51] A. Fathy and H. Rezk, "Parameter estimation of photovoltaic system using imperialist competitive algorithm," Renewable Energy, vol. 111, pp. 307-320, 2017/10/01/ 2017.

[52] E. Atashpaz-Gargari and C. Lucas, "Imperialist competitive algorithm: An algorithm for optimization inspired by imperialistic competition," in 2007 IEEE Congress on Evolutionary Computation, 2007, pp. 4661-4667.

[53] X.-S. Yang, "Chapter 8 - Firefly Algorithms," in Nature-Inspired Optimization Algorithms, ed Oxford: Elsevier, 2014, pp. 111-127. 
[54] I. M. M. SALEH, R. ALI, and H. ZHANG, "Simplified mathematical model of proton exchange membrane fuel cell based on horizon fuel cell stack," Journal of Modern Power Systems and Clean Energy, vol. 4, pp. 668-679, October 012016. 